\title{
Cyprinid swimming behaviour in response to turbulent flow
}

\author{
Ana T. Silva ${ }^{\mathrm{a}, *}$, Christos Katopodis $^{\mathrm{b}}$, José M. Santos ${ }^{\mathrm{a}}$, Maria T. Ferreira ${ }^{\mathrm{a}}$, António N. Pinheiro ${ }^{\mathrm{c}}$ \\ a Forest Research Centre, Instituto Superior de Agronomia, Technical University of Lisbon, Tapada da Ajuda, 1349-017, Lisboa, Portugal \\ ${ }^{\mathrm{b}}$ Katopodis Ecohydraulics Ltd., 122 Valence Avenue, Winnipeg, MB, Canada R3 T 3W7 \\ ' CEHIDRO, Instituto Superior Técnico, Technical University of Lisbon, Av. Rovisco Pais, 1049-001 Lisboa, Portugal
}

\section{A R T I C L E I N F O}

\section{Article history:}

Received 4 August 2011

Received in revised form 30 March 2012

Accepted 8 April 2012

Available online 5 May 2012

\section{Keywords:}

Iberian barbel

Swimming behaviour

Pool-type fishway

Turbulence

Eddies

Acoustic Doppler Velocimeter (ADV)

\begin{abstract}
A B S T R A C T
Turbulence is a complex phenomenon which commonly occurs in river and fishway flows. It is a difficult subject to study, especially biologically, yet turbulence may affect fish movements and fish passage efficiency. Studies on quantifying fish responses to turbulence, particularly within fishways, are lacking. This study investigated the swimming behaviour of 140 adult Iberian barbel (Luciobarbus bocagei) of two size-classes (small fish: $15 \leq \mathrm{TL}<25 \mathrm{~cm}$, large fish: $25<\mathrm{TL} \leq 35 \mathrm{~cm}$ ) under turbulent flow conditions created by three submerged orifice arrangements in an experimental pool-type fishway: (i) offset orifices, (ii) straight orifices and (iii) straight orifices with a deflector bar of $0.5 b_{0}$ located at $0.2 L$ from the inlet orifices, where $b_{0}$ is the width of the square orifices ranging from 0.18 to $0.23 \mathrm{~m}$ and $L$ is the pool length $(1.90 \mathrm{~m})$, Water velocity and turbulence (turbulent kinetic energy, Reynolds shear stress, turbulence intensity and eddy size) were characterized using a 3D Acoustic Doppler Velocimeter (ADV) and were related with fish swimming behaviour. The influence of turbulent flow on the swimming behaviour of barbel was assessed through the number of successful fish passage attempts and associated passage times. The amount of time fish spent in a certain cell of the pool (transit time) was measured and related to hydraulic conditions. The highest rates of passage and the corresponding lowest times were found in experiments conducted with offset orifices. Although size-related behavioural responses to turbulence were observed, Reynolds shear stress appeared as one of the most important turbulence descriptors explaining fish transit time for both size-classes in experiments conducted with offset and straight orifices; furthermore, swimming behaviour of larger fish was found to be strongly affected by the eddies created, in particular by those of similar size to fish total length, which were mainly found in straight orifices with a deflector bar arrangement. The results provide valuable insights on barbel swimming behavioural responses to turbulence, which may help engineers and biologists to develop effective systems for the passage of this species and others with similar biomechanical capacities.
\end{abstract}

(C) 2012 Elsevier B.V. All rights reserved.

\section{Introduction}

Freshwater systems are one of the most modified ecosystems on earth (Saunders et al., 2002), as a result of anthropogenic overexploitation (Arthington and Welcomme, 1995). For a number of decades, the natural flow regimes of rivers were substantially altered by the burgeoning construction of dams, weirs and other barriers, which blocked and delayed migration of fish, leading to a dramatic decline of many species (Cowx and Welcomme, 1998; Knaepkens et al., 2007). Thus, ecological continuity, in particular longitudinal connectivity, has become a major factor in the

\footnotetext{
* Corresponding author at: Departamento de Engenharia Florestal, Instituto Superior de Agronomia, Tapada da Ajuda, 1349-017 Lisboa, Portugal.

Tel.: +351213653 380; fax: +351213653 338 .

E-mail address: anamtsilva@isa.utl.pt (A.T. Silva).
}

restoration of regulated river systems, with, considerable efforts devoted to the development and improvement of fish passage structures for multiple species and life-stages. Despite advances in biologically oriented fishway research over several decades, efforts were mainly focused on anadromous fish species (i.e. fish that spend most of their lives in the sea and migrate to fresh water to spawn) (Baras et al., 1994; Gowans et al., 2003; Katopodis, 2005). Considerable lack of knowledge exists on the suitability and efficiency of fish pass designs for potamodromous species (i.e. migratory fish whose migrations occur entirely within freshwater) (Katopodis, 2005), which are the predominant group of migratory fish encountered in Mediterranean rivers (Baras et al., 1994; Lucas and Frear, 1997; Santos et al., 2005).

Pool and weir fishways are one of the most common types of fish pass (FAO/DVWK, 2002) used to facilitate upstream movement of fish. Although their design criteria are reasonably well-understood for the passage of salmonids (Bell, 1986; Clay, 1995; Ead et al., 2004; 


\begin{tabular}{|c|c|}
\hline \multicolumn{2}{|c|}{ Nomenclature } \\
\hline$a_{\mathrm{e}}$ & area of the eddy \\
\hline$A_{\mathrm{o}}$ & area of the submerged orifice \\
\hline$A_{\mathrm{p}}$ & total area of the pool \\
\hline$B$ & pool width \\
\hline$b_{\mathrm{o}}$ & width of the submerged orifice \\
\hline$g$ & acceleration of gravity $\left(9.81 \mathrm{~m}^{2} / \mathrm{s}\right)$ \\
\hline$h_{\mathrm{m}}$ & pool mean water depth \\
\hline$L$ & pool length \\
\hline $\mathrm{Le}_{\Delta x}$ & maximum longitudinal diameter of the eddies \\
\hline $\operatorname{Le}_{\Delta y}$ & maximum transversal diameter of the eddies \\
\hline$L_{\mathrm{lf}}$ & length of the larger fish \\
\hline$L_{\mathrm{sf}}$ & length of the smaller fish \\
\hline$P_{\mathrm{V}}$ & volumetric power dissipation in a pool \\
\hline$Q$ & fishway discharge \\
\hline$T$ & sampling period \\
\hline TI & turbulence intensity \\
\hline TKE & turbulent kinetic energy \\
\hline $\mathrm{TL}$ & fish total length \\
\hline$U$ & average local velocity \\
\hline $\mathrm{TL}_{\mathrm{sf}}$ & small fish total length \\
\hline & large fish total length \\
\hline $\begin{array}{l}u_{r m s 1}^{2}, u \\
u^{\prime}\end{array}$ & $\begin{array}{l}m s 2, u_{r m s 3}^{2} \text { root mean square values of } u, v, w \\
\text { fluctuating component of velocity at sampling time } \\
T\end{array}$ \\
\hline$V_{\mathrm{o}}$ & maximum flow velocity at orifice \\
\hline$x, y, z$ & coordinates \\
\hline$\Delta h$ & water level difference between two adjacent pools \\
\hline$\rho$ & water density \\
\hline$-\rho \overline{u_{i}^{\prime} u_{j}^{\prime}}$ & Reynolds shear stress at the $x y$ plane \\
\hline$\tau$ & Reynolds shear stress \\
\hline$\tau_{x y}$ & Reynolds shear stress at the $x y$ component. \\
\hline
\end{tabular}

Katopodis, 2005), thus far the biological criteria to ensure suitability of these devices for cyprinid and other freshwater species are not well understood and require further research (Katopodis, 2005). Fish passage efficiency for various fishway types built in a variety of locations was found to be lower for non-salmonids for than for salmonids (Noonan et al., 2011). Improvements on fishway design criteria are known to depend on the understanding of how hydrodynamic cues are used by fish to guide fine-scale swim path selection. Hence variation on hydrodynamic variables such as velocity, water depth and turbulence which is strongly influenced by pool dimensions, design configuration, size of orifices or notches, as well as fishway slope and discharge, are determining factors in fish passage efficiency, fish swimming ability and behaviour (Silva et al., 2010, 2011).

Turbulence is defined as the three-dimensional, time and spatially dependent heterogeneous motion of rapid flow velocity fluctuations which result from the superposition of chaotic cortical flows of multiple strengths and sizes (Kirkbride, 1993). This hydraulic variable affects fish swimming costs (Liao et al., 2003), capture efficiency (Enders et al., 2003), habitat selection (Cotel et al., 2006) and fish density (Smith et al., 2006). Depending on its magnitude, turbulence may attract or repel fish, triggering or preventing their migratory movements. It has been well documented that turbulence increases the cost of fish locomotion (Pavlov et al., 1982; Enders et al., 2003) and at extremely high levels, causes body injuries or even fish mortality (Cada et al., 1999; Odeh et al., 2002). Nonetheless, recent studies have also shown that fish might reduce locomotory costs by exploiting the energy of vortices generated by water moving past physical structures or propulsive movements of other fishes (Liao, 2007; Przybilla et al., 2010), or their own (Liao et al., 2003). The effects of turbulence on fish energetic costs have been deemed two fold. In the past few decades, several of the most important turbulent descriptors for migrating fish have been identified: turbulent kinetic energy (TKE), Reynolds shear stress $(\tau)$, turbulence intensity (TI), strain, eddy length scale, orientation, and vorticity (Pavlov et al., 2000; Tritico and Cotel, 2010; Silva et al., 2011). Turbulent kinetic energy, which corresponds to the kinetic energy associated with fluctuating velocity at a given point (Rodi, 1980), was shown to affect fish swimming performance (Odeh et al., 2002; Silva et al., 2011) by increasing swimming costs (Enders et al., 2005). Enders et al.(2005), who focused on developing a swimming cost model for juvenile Atlantic salmon (Salmo salar) by estimating the total costs of swimming in a respirometer, found that total swimming costs increased with the increment of turbulent kinetic energy.

Reynolds shear stress is defined by the continuous transfer of momentum between adjacent viscous water masses of different velocities, intersecting or moving near each other (Tennekes and Lumley, 1972). The generated force, exerted parallel to the fish body, has a strong impact on fish swimming performance and stability (Odeh et al., 2002; Silva et al., 2011) and at extremely high levels it may cause severe injury or mortality (Cada et al., 1999; Odeh et al., 2002). Furthermore, the impact of this tension depends on its orientation towards the body of the fish, as demonstrated by Silva et al. (2011), who found that the longitudinal component of Reynolds shear stress $\left(\tau_{x y}\right)$ affects fish the most. Another common turbulent descriptor is turbulence intensity, which is defined as a normalized measure of variation in velocity magnitude relative to the local average speed where the measurement is made (Pavlov et al., 2000; Odeh et al., 2002), This may decrease fish swimming speed for values higher that $2 / 3$ of the total length of the fish as found by (Lupandin, 2005) in his study on the effect of turbulence intensity in the swimming speed of perch (Perca fluviatilis) of different size-classes.

Turbulent eddies are typical vortical structures that occur in unsteady flows. These coherent rotating structures in the fluid are often described by their diameter, orientation and rate of rotation or vorticity. These type of turbulent structures, result by either connecting to an interface (solid-liquid such as the bed surface or between two fluids such as the air-water interface) and may be visualized as cylinders of fluid spanning two interfaces, or by connecting to themselves in a toroidal or 'vortex ring' shape (Tritico and Cotel, 2010). These turbulent structures are a subject of intensive study in the field of hydraulics (see Shah and Tachie, 2009 among others), yet very little information exists on the effects of eddies on the swimming behaviour of fish. The effects of vortex structures on animal behaviour, such as bird migratory patterns, has a long history of research in aerodynamics, particularly on soaring birds that can maintain flight without wind flapping by taking advantage of rising air currents (Hedenström, 1993; Ristroph et al., 2011; Sapir et al., 2011). Similar hydrodynamic research on the effects of eddies in fish swimming performance, is more recent (Pavlov et al., 2000; Lupandin, 2005; Liao, 2007). Eddy diameter, vorticity and orientation relative to the fish, as being primary variables, were shown to strongly affect fish orientation, stability and swimming speed (Tritico and Cotel, 2010). In their study on testing the effects of turbulence on the stability and swimming speed of creek chub, Tritico and Cotel (2010) found that stability challenges on fish occurred for eddy diameters larger than $50-75 \%$ of the fish body total length, and that critical swimming speed reduced more in turbulent flow dominated by large horizontal eddies than large vertical eddies.

This study was conducted with Iberian barbel (Luciobarbus bocagei, Steindachner, 1864), a cyprinid endemic to the Iberian 
Peninsula, occurring in almost all of the river basins in northern and central Portugal (Lobón-Cerviá, 1982; Geraldes et al., 1993; Santos et al., 2005). The migratory pathways for feeding and spawning purposes of this rheophilic potamodromous species (i.e. freshwater fish that prefer water currents), include rivers with turbulent flows which occur over considerable distances (Smith, 1991). Yet, there is still very little information on how this species responds to the kinematic descriptors of turbulence and to the characteristics of the typical vortical structures (eddy shape, size, vorticity, orientation) that occur in unsteady flows. A better understanding of this biological-physical interplay would provide important insights on the influence of turbulence on the swimming behaviour of this species and other species of similar biomechanical attributes, which is critical information to improve the efficiency of fishways for these species, allowing the long-term sustainability of such populations.

The primary objective of this study was to investigate the effects of turbulence (TKE, Reynolds shear stress, TI and eddy size) on the swimming behaviour of two-size-classes of Iberian barbel, under turbulent conditions created by three different orifice arrangements in an experimental pool-type fishway. It was hypothesized that different orifice arrangements generate dissimilar turbulent conditions, which impact fish swimming behaviour and performance differently, influencing fish passage efficiency and transit times. A secondary hypothesis was that an intra-specific variation on behaviour could be identified between the two size-classes of barbel, and this would likely be dependent on the swimming capacity to respond to the different turbulent descriptors. The last hypothesis was that the magnitude, orientation, and size of eddies may strongly influence behaviour, swimming stability and performance with possible fish size differences.

\section{Materials and methods}

\subsection{Experimental setup}

Adult Iberian barbel $(N=140)$ were captured by means of electrofishing (Electrocatch International, Sarel model WFC7_HV, Wolverhampton, UK) with low voltage (250V) at the River Sorraia, the largest tributary of the River Tagus (central Portugal). Sampling was performed during May 2009, since April-May is the natural reproductive migration season for this species (Santos et al., 2005). Test fish ranged from 15 to $35 \mathrm{~cm}$ and according to their total length $(\mathrm{TL})$ were separated into two different sizeclasses: small adults $(N=70,15 \leq(\mathrm{TL})<25 \mathrm{~cm}$, mean \pm SD $(\mathrm{cm})$ : $19.60 \pm 2.60)$ and large adults $(N=70,25 \leq \mathrm{TL}<35 \mathrm{~cm}$, mean \pm SD $(\mathrm{cm}): 28.95 \pm 3.46)$. Fish were kept in filtered and aerated holding tanks $(1.45 \mathrm{~m} \times 0.70 \mathrm{~m} \times 0.80 \mathrm{~m})$ at a density of 20 per tank, to recover from handling and transport stress, for at least one week prior to the experiments. Fish were fed daily with pond sticks (Tetra Pond) until $24 \mathrm{~h}$ prior to experimentation. Experiments were conducted in a full-scale pool-type fishway prototype at the Hydraulics and Environment Department of the National Laboratory for Civil Engineering (LNEC), in Lisbon. It consisted of a rectangular open-channel $(10.0 \mathrm{~m} \times 1.0 \mathrm{~m} \times 1.2 \mathrm{~m})$, featuring an upstream $(2.6 \mathrm{~m} \times 1.0 \mathrm{~m} \times 1.2 \mathrm{~m})$ and a downstream tank $(4.0 \mathrm{~m} \times 3.0 \mathrm{~m} \times 4.0 \mathrm{~m})$. Silva et al. (2011) provide more details on fish handling and test equipment.

To test how Iberian barbel respond to different levels of turbulence, fish were tested during May to July 2009 in different hydraulic conditions (Table 1) created in an experimental pooltype fishway by, varying flow discharge and orifice arrangement: (a) offset orifices (i.e. orifices alternating from side to side in the pools); (b) straight orifices (i.e. orifices aligned on one side of the

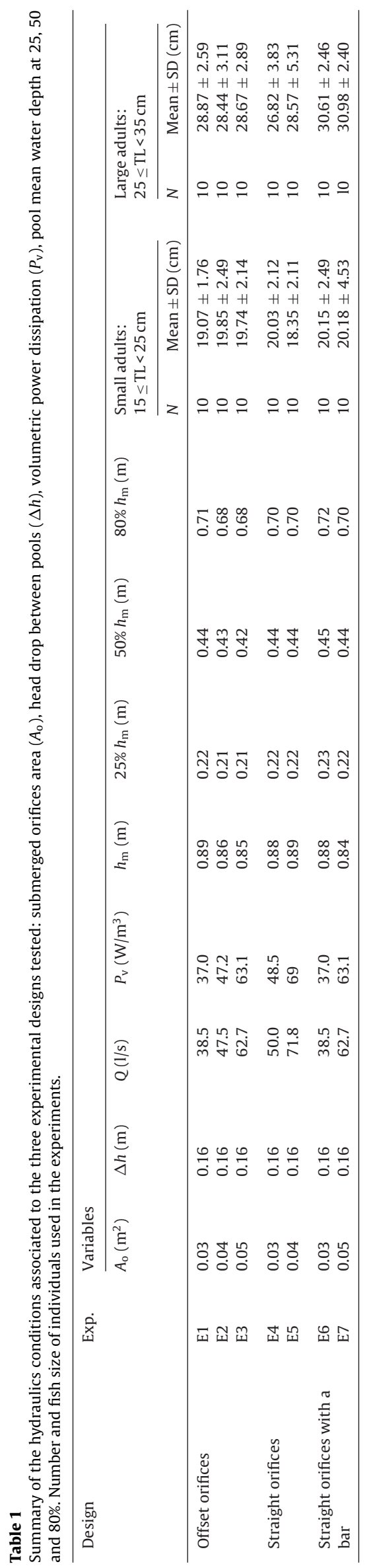


a)

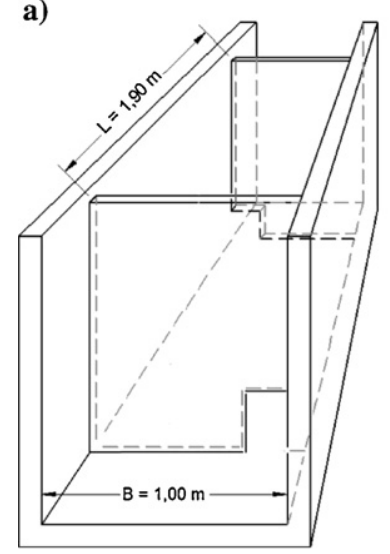

b)

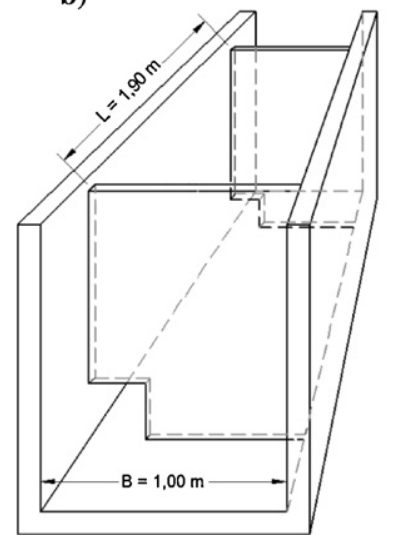

c)

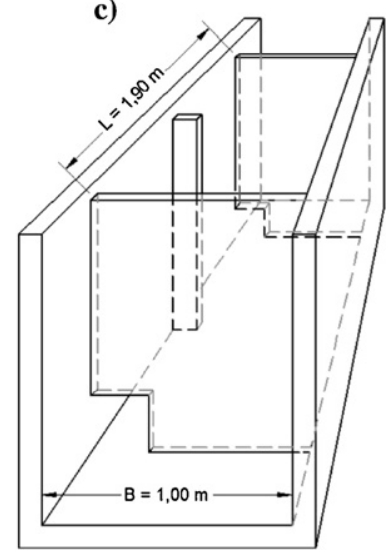

Fig. 1. Schematic of orifice arrangements tested: (a) offset orifices; (b) straight orifices; (c) straight orifices with a bar.

pools); and (c) straight orifices with a deflector bar protruding $0.5 b_{0}(0.09,0.10$ and $0.12 \mathrm{~cm})$ from the pool side and located at $0.20 L$ from the inlet orifice, where $b_{0}$ is the width of the square orifices and $L$ is the pool length (Fig. 1). Silva et al. (2010) in their study on the passage efficiency of offset and straight orifices for Iberian barbel in a pool-type fishway found that straight orifices create a jet flow of very high velocity which makes upstream fish movements difficult. A deflector bar between two consecutive orifices was used in the present work as an attempt to reduce such critical hydraulic conditions for fish. To this end, both the width and the location of the bar were choices based on the results found by Alvarez (2009). This study focused on the hydraulic characterization of turbulence in pool-type fishways with different orifice arrangements, in which the former combination of width and location of the bar was likely to create hydraulic conditions more favourable for upstream fish movements. Experiments, which lasted $1.5 \mathrm{~h}$, were conducted using two adult fish simultaneously, one of each size-class. Fish were randomly removed from the holding tanks and held at the downstream tank for acclimation for at least $1 \mathrm{~h}$ prior to experimentation. A panel with a fine mesh screen located within the downstream tank prevented fish from entering the flume before experiments began. To avoid possible bias in the outcome of the experiments, as a result of learning based effects (Mallen-Cooper, 1994), each fish was used only once in the study. In total 70 trials were conducted by testing seven different hydraulic conditions (Table 1 ) with 10 replicates each.

\subsection{Experimental trials}

Experiments were performed with uniform flow (i.e. identical depth at equivalent points within each of the six pools), with a head drop between two consecutive pools $(\Delta h)$ of $0.16 \mathrm{~m}$. This corresponds to a potential velocity $\left(V_{0}\right)$ of $1.77 \mathrm{~m} / \mathrm{s}$, based on calculation from the formula $V_{0}=\sqrt{2 g \Delta h}=1.77 \mathrm{~m} / \mathrm{s}$, where $g$ is the acceleration due to gravity $\left(9.81 \mathrm{~m} / \mathrm{s}^{2}\right)$. Measurements of water surface elevations for each experiment were conducted by using a transparent grid attached to the flume side wall which determined mean flow depth $\left(h_{\mathrm{m}}\right)$ in each pool. The velocity fields in the flume were characterized by means of a NORTEK AS 3D Acoustic Doppler Velocimeter (ADV) at a frequency of $25 \mathrm{~Hz}$. At this rate, 2500 instantaneous measurements of velocity were recorded for each sample point $(n=48)$ for a sampling period of $90 \mathrm{~s}$, which is the sampling period determined by Silva et al. (2010) to provide convergent statistics of mean water velocity and turbulence parameters. Measurements were taken on horizontal planes parallel to the flume bottom at $25 \%, 50 \%$ and $80 \%$ of the pool mean depth in the 2 nd downstream pool, to ensure developed flow occurred. These measurements were used to determine: time-averaged velocities, flow patterns, fluctuating velocities, turbulent kinetic energy, Reynolds shear stress and turbulence intensity.

In this study, turbulent kinetic energy (TKE), was calculated according to Rodi (1980) as:

TKE $=\frac{1}{2}\left(u_{r m s 1}^{2}+u_{r m s 2}^{2}+u_{r m s 3}^{2}\right)$
with, $u_{r m s}=\sqrt{\overline{{u^{\prime}}^{2}}}=\left[\frac{1}{T \int_{0}^{T} u^{\prime 2} d t}\right]^{1 / 2}$

where, $u_{r m s 1}^{2}, u_{r m s 2}^{2}$ and $u_{r m s 3}^{2}$ are respectively the root mean square values of the fluctuating components of velocity on the $x, y, z$ orthogonal coordinate system and $u^{\prime}$ is the fluctuating component of velocity at the sampling time $T$. To evaluate and compare values between the different hydraulic conditions tested, as well as to develop universal expressions, turbulent kinetic energy was normalized using the potential velocity $\left(\sqrt{\mathrm{TKE} / V_{0}}\right)$.

Reynolds shear stress $(\tau)$, which derives from the three normal stress terms in the Reynolds-averaged-Navier-Stokes (RANS) equation (Tennekes and Lumley, 1972) was defined for the plane $X Y$ as:

$\tau_{x y}=-\rho \overline{u_{i}^{\prime} u_{j}^{\prime}}, \quad$ with $i \neq j$

where $\rho$ is the water density $\left(1000 \mathrm{~kg} / \mathrm{m}^{3}\right)$ and $i, j$ are the two components in two-dimensional space. Reynolds shear stress for the $X Y$ plane was normalized by using the potential velocity $\left(\tau_{x y} / \rho V_{0}^{2}\right)$.

Turbulence intensity, a turbulent descriptor commonly quantified in studies using fish (Tritico and Cotel, 2010) was calculated by using the following equation:

$\mathrm{TI}=\left[\frac{(1 / 2)\left(u_{r m s 1}^{2}+u_{r m s 2}^{2}+u_{r m s 3}^{2}\right)}{U^{2}}\right]$

where $U$ is the average local velocity.

To study the possible influence of eddies observed in the three experimental configurations on fish swimming behaviour, maximum longitudinal $\left(\mathrm{Le}_{\Delta x}\right)$ and transversal $\left(\mathrm{Le}_{\Delta y}\right)$ diameter of the eddies created within the pool were determined. Streamlines outlined eddy contours which were defined by tracing the velocity vectors, and their respective longitudinal and transversal diameters were measured in the horizontal plane at $0.25 h_{\mathrm{m}}$. A qualitative approach based on the ratio between maximum longitudinal $\left(\operatorname{Le}_{\Delta x}\right)$ 
a)

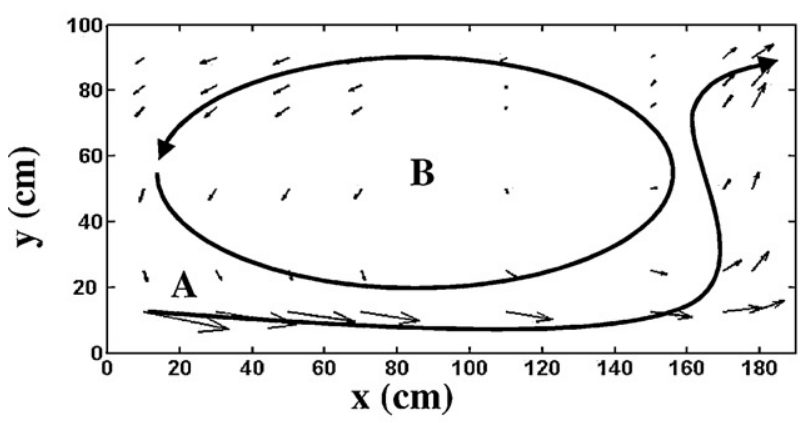

c)

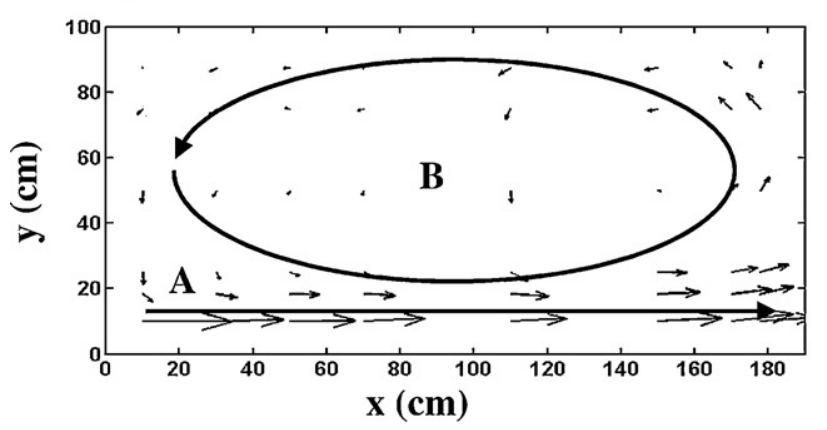

e)

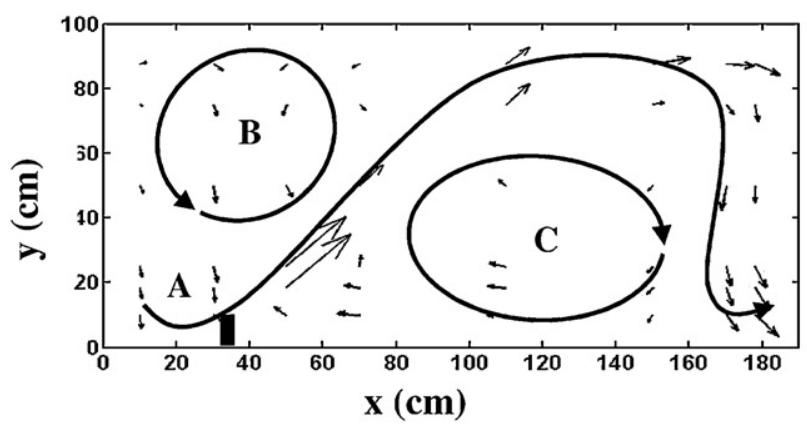

b)

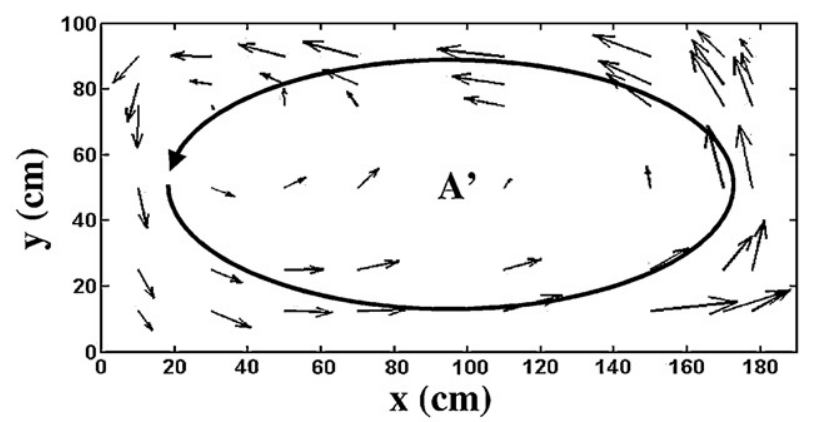

d)

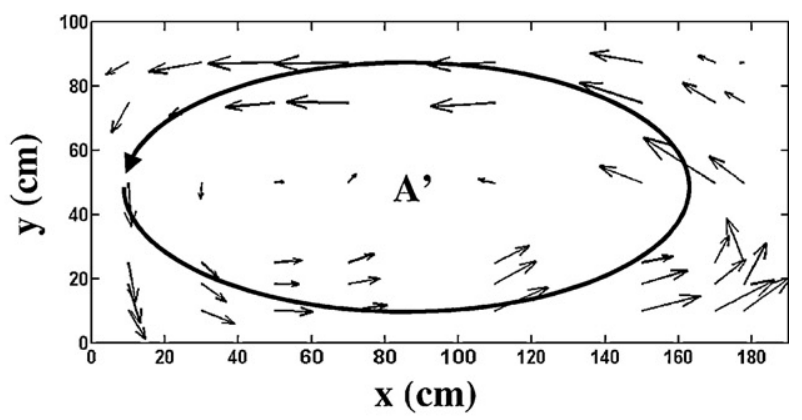

f)

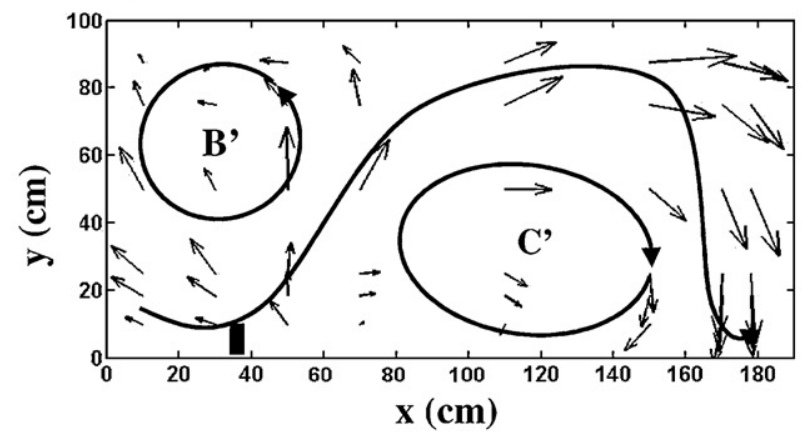

reference vector $(\longrightarrow)$

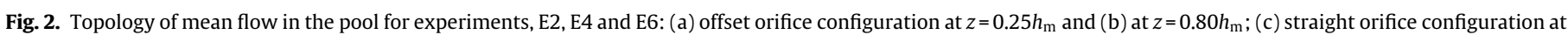

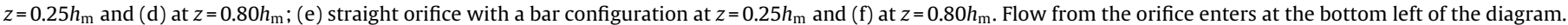

and transversal $\left(\operatorname{Le}_{\Delta y}\right)$ horizontal eddy diameters and the total length of the fish tested (TL) was also determined.

Flow characterization was supplemented by direct observations and video recording of fish movements within the 2 nd downstream pool to identify patterns of fish movements. Further details on the video recording system can be found in Silva et al. (2011).

\subsection{Video analysis}

Movements of fish were recorded and subsequently analyzed by using the IVision Labview software from National Instruments (http://www.ni.com). To aid video analysis, a $1.90 \mathrm{~m}$ long by $1.00 \mathrm{~m}$ wide reference grid containing 15 contiguous sequentially numbered cells (each, $0.38 \mathrm{~m}$ length $\times 0.33 \mathrm{~m}$ width) was placed in the pool within the camera field of view. From the video recordings, fish location and the time spent by fish in each cell of the grid (transit time) were determined and further analyzed in combination with the hydraulic data. An individual was considered to occupy one cell, when more than half of its body length was within the cell's boundaries. Fish behaviour within the pool was also analyzed and related with the size of observed eddies.

\subsection{Statistical analysis}

Data were tested for normality with the Shapiro-Wilk test. Nonparametric tests were conducted for violations of the assumption of normality and homogeneity of variance. Mann-Whitney Rank Sum test was used to detect significant differences on velocity and turbulence between hydraulic regions created in each experimental configuration, and to search for significant differences on the number of successful passages and the respective times taken by fish in each size-class and configuration. To assess the hypotheses that for each fish size-class, the rate of success and the respective time of passage were different among hydraulic configurations, the Kruskal-Wallis ANOVA was applied. Possible correlations between fish transit time in each cell and the respective mean values of velocity, TKE, TI and Reynolds shear stress, in each experimental configuration were tested with the Spearman rank coefficient. 
Table 2

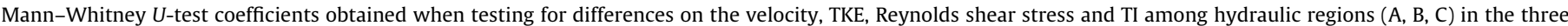
experimental designs.

\begin{tabular}{|c|c|c|c|c|c|c|}
\hline \multirow[t]{2}{*}{ Design } & \multirow[t]{2}{*}{ Experiments } & \multirow[t]{2}{*}{ Regions } & \multicolumn{4}{|c|}{ Hydraulic variables } \\
\hline & & & $v(\mathrm{~m} / \mathrm{s})$ & $\operatorname{TKE}\left(\mathrm{m}^{2} / \mathrm{s}^{2}\right)$ & $-\rho u^{\prime} v^{\prime}\left(\mathrm{N} / \mathrm{m}^{3}\right)$ & $\mathrm{TI}$ \\
\hline \multirow[t]{3}{*}{ Offset orifices } & E1 & A-B & $5.11^{* * *}$ & $5.28^{* * *}$ & $3.83^{* * *}$ & $0.38(\mathrm{~ns})$ \\
\hline & E2 & $A-B$ & $5.04^{* * *}$ & $5.02^{* * *}$ & $3.42^{* * *}$ & $-2.76^{* *}$ \\
\hline & E3 & A-B & $5.30^{* * *}$ & $4.29^{* * *}$ & $3.36^{* * *}$ & $-2.53^{*}$ \\
\hline \multirow[t]{2}{*}{ Straight orifices } & E4 & A-B & $4.39^{* * *}$ & $4.79^{* * *}$ & $4.61^{* * *}$ & $-0.65(\mathrm{~ns})$ \\
\hline & E5 & A-B & $5.22^{* * *}$ & $5.53^{* * *}$ & $5.44^{* * *}$ & $-1.18(\mathrm{~ns})$ \\
\hline \multirow[t]{6}{*}{ Straight orifices with a bar } & E6 & A-B & $4.48^{* * *}$ & $3.24^{* * *}$ & $0.33(\mathrm{~ns})$ & $2.47^{*}$ \\
\hline & & A-C & $3.81^{* * *}$ & $2.47^{* *}$ & -0.08 (ns) & $3.24^{* *}$ \\
\hline & & $\mathrm{B}-\mathrm{C}$ & $-0.84(\mathrm{~ns})$ & $-0.53(\mathrm{~ns})$ & $-0.21(\mathrm{~ns})$ & 0.53 (ns) \\
\hline & E7 & A-B & $3.38^{* * *}$ & 1.47 (ns) & -0.49 (ns) & $-3.91^{* * * *}$ \\
\hline & & A-C & $3.58^{* * *}$ & $3.52^{* * *}$ & $-2.08^{*}$ & $-1.90(\mathrm{~ns})$ \\
\hline & & $\mathrm{B}-\mathrm{C}$ & $-0.70(\mathrm{~ns})$ & $1.41(\mathrm{~ns})$ & $-2.32^{*}$ & 1.50 (ns) \\
\hline
\end{tabular}

ns, not significant.

Significant in $P<0.05$

** Significant in $P<0.01$.

*** Significant in $P<0.001$

Multiple stepwise forward regressions were employed for fish transit time as the dependent variable and velocity and turbulent parameters as independent variables. To meet the normality requirements of parametric analysis, data were $\log (x+1)$ transformed. Durbin-Watson statistics (D) (Durbin and Watson, 1951) were used to test for first-order autocorrelation in the residuals of each configuration. Analyses were performed using data collected at $z=0.25 h_{\mathrm{m}}$, as, in all experiments, fish preferentially moved close to the bottom of the fishway (see Section 3.2.2). The statistical procedure was carried out using STATISTICA (STATSOFT, INC., 2000) for a significance level of $\alpha=0.05$.

\section{Results}

\subsection{Turbulent flow}

\subsubsection{Flow topology and velocities}

In all experiments, water velocity was found to be lower near the water surface $\left(z=0.80 h_{\mathrm{m}}\right)$ than near the pool floor $\left(z=0.25 h_{\mathrm{m}}\right)$ (Fig. 2). In experiments conducted with offset orifices, near the bottom of the flume $\left(z=0.25 h_{\mathrm{m}}\right.$; Fig. $\left.2 \mathrm{a}\right)$ two distinct areas could be defined: (a) a main flow (region $A$ ) with high velocities (mean $\pm S D$ $(\mathrm{m} / \mathrm{s}): 0.56 \pm 0.37$; Table 2$)$ travelling between two consecutive orifices occupying $41 \%$ of the total area of the pool $\left(A_{\mathrm{p}}\right)$ and a recirculation region (region $B$ ) with reverse flow direction (counter-clockwise) and significantly lower velocities (mean \pm SD $(\mathrm{m} / \mathrm{s}): 0.20 \pm 0.07$; Table 2 ) and b) large counter-clockwise eddies which extend through $59 \%$ of $A_{\mathrm{p}}$, next to the main flow (Fig. 3a). Near the surface $\left(z=0.80 h_{\mathrm{m}}\right.$; Fig. $\left.2 \mathrm{~b}\right)$, a uniform recirculation area (region $A^{\prime}$ ) with lower velocities (mean \pm SD (m/s): $0.25 \pm 0.09$; Table 2 ) could be found. In experiments conducted with the straight orifice arrangement a primary flow (region A) travelling directly between the two straight orifices with high velocities (mean \pm SD $(\mathrm{m} / \mathrm{s}): 0.47 \pm 0.22$; Table $2 ; 33 \%$ of $A_{\mathrm{p}}$ ) and a contiguous recirculation area (region $\mathrm{B} ; 67 \%$ of $A_{\mathrm{p}}$ ) of much lower velocities (mean $\pm \mathrm{SD}$ $(\mathrm{m} / \mathrm{s}): 0.16 \pm 0.06 \mathrm{~m} / \mathrm{s}$; Table 2$)$ and large eddies (Fig. $3 \mathrm{~b})$, were created at the deepest level $\left(z=0.25 h_{\mathrm{m}} ;\right.$ Fig. 2c). Near the surface $\left(z=0.80 h_{\mathrm{m}}\right)$ this orifice arrangement created a counter-clockwise recirculation area (region $A^{\prime}$; Fig. 2d) with negligible velocities (mean \pm SD: $0.16 \pm 0.06$; Table 2). From all three experimental designs tested at the deepest water level $\left(z=0.25 h_{\mathrm{m}}\right)$, average water velocity was lower in experiments conducted with straight orifices with a deflector bar $(0.23 \mathrm{~m} / \mathrm{s})$. In this case, three different regions could be distinguished: a primary flow (region A; Fig. 2e and f) of high velocities (mean $\pm \mathrm{SD}(\mathrm{m} / \mathrm{s})$ : $0.36 \pm 0.22$; Table 2 ) flowing from the upstream orifice towards the deflector bar and then turning to the opposite sidewall towards to the downstream orifice, occupying c. $40 \%$ of $A_{\mathrm{p}}$; a secondary region in the counter-clockwise direction (region B; Fig. 2e and f) of lower velocities (mean \pm SD $(\mathrm{m} / \mathrm{s}): 0.14 \pm 0.19$; Table 2 ) located between the main flow and the upstream cross-wall, and a third region of clockwise rotation (region C; Fig. 2e and f), of very low velocities (mean $\pm \mathrm{SD}(\mathrm{m} / \mathrm{s})$ : $0.16 \pm 0.05$; Table 2 ) created immediately below the deflector bar, constrained between $0.42 L-0.74 L$ and $0.12 B-0.5 B$ and occupying c. $25 \%$ of $A_{\mathrm{p}}$. Significant differences in water velocity were found between the primary flow and region $B$ and $C$ (Table 2). It was observed that in this configuration generated eddies had a negatively skewed distribution (Fig. 3c) and their size varied the most, when compared to the eddies generated by offset and straight orifices. Depth-related variations of flow pattern were not found in the experiments involving straight orifices with a bar (Fig. 2e and f).

\subsubsection{Turbulence}

Fig. 4, gives the contours of normalized turbulent kinetic energy for the three experimental designs tested. TKE strongly varied with water depth, decreasing near the water surface. In all experiments the highest values of TKE were created near the bottom of the flume $\left(z=0.25 h_{\mathrm{m}}\right)$ along the primary flow (see Section 3.1.1) decreasing in the remaining areas. Significant differences on TKE were found between the main flow and region $B$ and/or $C$ in all the experiments (Table 2). The straight orifice arrangement with a deflector bar seemed to have created the highest values of sqrt (TKE) $\left(0.47 V_{0}\right)$, when compared with those found in experiments conducted with offset and straight orifices, $0.29 V_{0}$ and $0.32 V_{0}$, respectively (Fig. 4a, c and e). The range for sqrt (TKE) was $0.04 V_{o}$ to $0.47 V_{0}$ for the straight orifice arrangement with a deflector bar, the largest variation observed between the three configurations tested. At the deepest pool level $\left(z=0.80 h_{\mathrm{m}}\right)$, sqrt (TKE) was lowest in all configurations (Fig. $4 \mathrm{~b}, \mathrm{~d}$ and f). At this depth sqrt (TKE) variation was similar to the experiments conducted with offset $\left(0.15 V_{0}\right)$ and straight $\left(0.12 V_{0}\right)$ orifices in which the highest sqrt (TKE) values $\left(0.32 V_{o}\right)$ were reached near the cross-wall opposite the orifice (Fig. $4 \mathrm{~b}$ and $\mathrm{d}$ ). In the experiments with straight orifices and a deflector bar, sqrt (TKE) was clearly higher $\left(0.10 V_{0}\right)$ upstream than downstream of the bar, decreasing towards region $C$ to values of $c$. $0.04 V_{0}$. 
a)

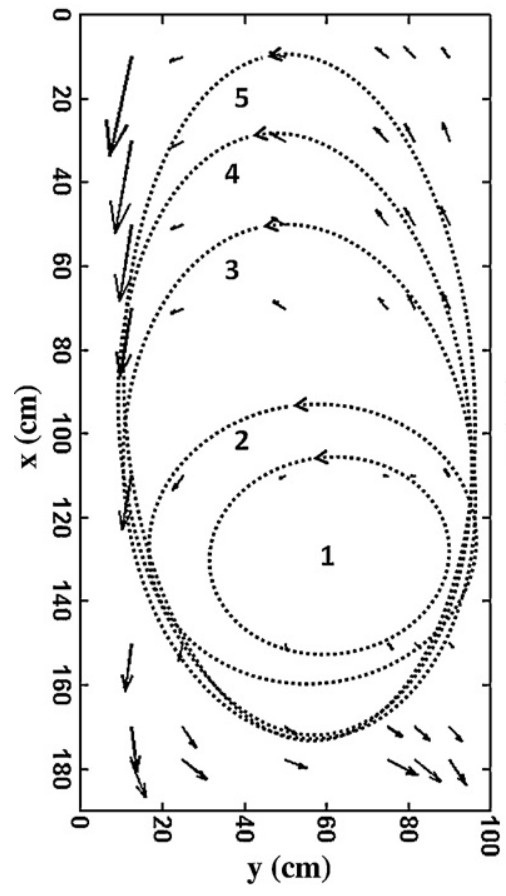

b)

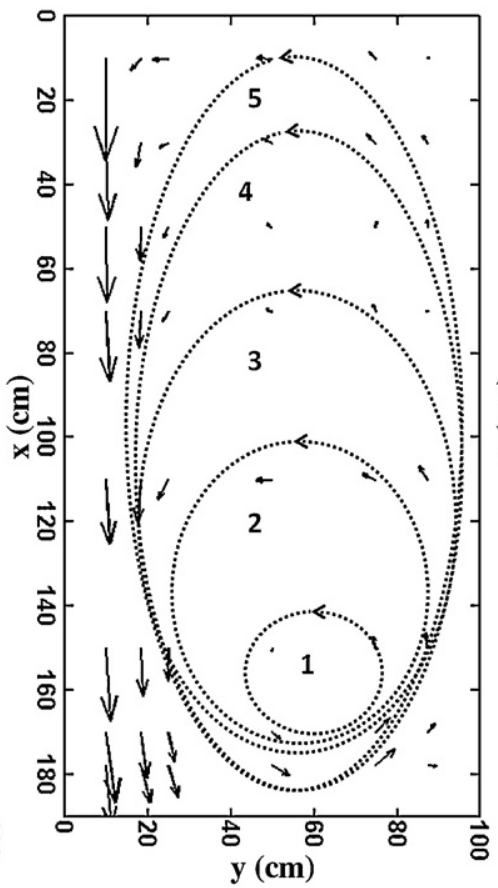

c)

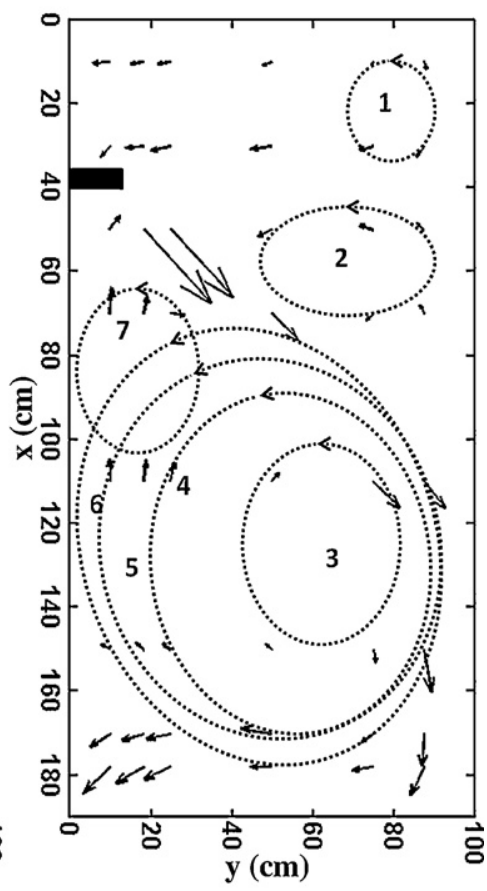

reference vector $(\longrightarrow)$

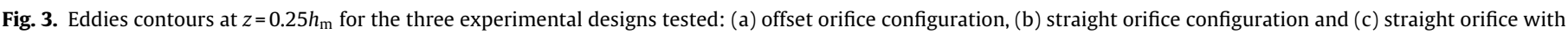
a bar configuration. Flow from the orifice enters at the upper left corner.

Contours of normalized Reynolds shear stress for the XY are plotted in Fig. 5. It is clear that this normalized horizontal component of the Reynolds shear stress decreased near the water surface where it reached negligible values c. $<0.001 V_{o}^{2}$ (Fig. 5b, d and f). This effect was highly pronounced in the experiments with straight orifices (Fig. 5c and d) and straight orifices with a bar (Fig. 5e and f). In the experiments with straight orifices, maximum absolute values of this hydraulic variable $\left(0.02 V_{\mathrm{o}}^{2}\right)$ were found at $z=0.25 h_{\mathrm{m}}$ in the main flow area (see Section 3.1.1) and decreased towards the opposite side-wall, where they remained almost negligible (Fig. 5c). A similar variation of the $X Y$ component of Reynolds shear stress was also observed in the experiments with offset orifices (Fig. 5a). Significant differences on this hydraulic parameter were found among the different hydraulic regions created in experiments with offset and straight orifices (Table 2). The introduction of a deflector bar between two straight orifices induced the highest variations of this hydraulic parameter at the deepest water level, where two distinct areas of different Reynolds shear stress values could be distinguished: (a) an area between the upstream cross-wall and the deflector bar $(0<L<0.20)$, where the highest values of horizontal Reynolds shear stress were reached $\left(<0.015 V_{0}^{2}\right)$ and (b) an area located between the deflector bar and the downstream cross-wall $(L>0.20)$, in which very low levels of horizontal Reynolds shear stress were found c. $<0.002 V_{0}^{2}$.

Maps of TI were created for the three experimental designs at $z=0.25 h_{\mathrm{m}}$ and $z=0.80 h_{\mathrm{m}}$ (Fig. 6). For all the experimental designs tested near the bottom of the pool $\left(z=0.25 h_{\mathrm{m}}\right)$, the straight orifice arrangement with a deflector bar generated the highest values of TI observed c. 4.24 in the main flow area (see Section 3.1.1). TI values decreased towards the remaining hydraulic areas (region B and C) and reached negligible values (c. $<0.06$ ), leading to significant differences on TI among these hydraulic regions (Table 2). Though variations of maximum TI from the bottom to the surface were not clear at the most superficial level $\left(z=0.80 h_{\mathrm{m}}\right)$, maximum TI values were also found to be higher in experiments with straight orifices and a deflector bar (4.20) when compared to experiments with offset or straight orifice arrangements (2.51 and 3.04, respectively).

\subsection{Fish}

\subsubsection{Fish passage efficiency}

Among the three tested configurations, the hydraulic conditions created by the offset orifice arrangement resulted in a significantly higher rate of passage for fish of both size classes (smaller fish: 61\%; larger fish: 78\%) when compared to straight orifices (smaller fish: 25\%; larger fish: 30\%) or straight orifices with a deflector bar (smaller fish: 55\%; larger fish: 15\%) (Kruskal-Wallis ANOVA: $P=0.0001$ ). Although in experiments conducted with offset and straight orifices larger fish exhibited higher passage efficiency, size-related differences on the rate of success were not found to be significant for each of these configurations (Mann-Whitney $U$ test: offset orifices, $Z=-0.82, P=0.409$; straight orifices, $Z=-0.34$, $P=0.726$ ). This result is in contrast with experiments for straight orifices with a deflector bar. In this case, a relationship was clearly evident (Mann-Whitney $U$-test: $Z=2.61, P=0.009$ ) as a high number of smaller fish passed (55\%), compared to a low number (15\%) of the larger fish which were successful (Fig. 7a).

The time taken by fish to successfully negotiate the fishway varied with the experimental configuration and fish size-class (Fig. 7b) The offset orifice arrangement seemed to be more suitable for both fish size-classes for upstream passage, as evident by the shortest transit times (mean \pm SE (min): $7.18 \pm 0.83$ ). Fish transit times in experiments with straight orifices (mean $\pm \mathrm{SE}(\mathrm{min}): 7.81 \pm 2.54)$ and straight orifices with a bar (mean $\pm \mathrm{SE}(\mathrm{min}): 7.57 \pm 2.12$ ) were longer for both size classes. Smaller fish experienced more difficulty in overcoming the hydraulic conditions created by the straight 
a)

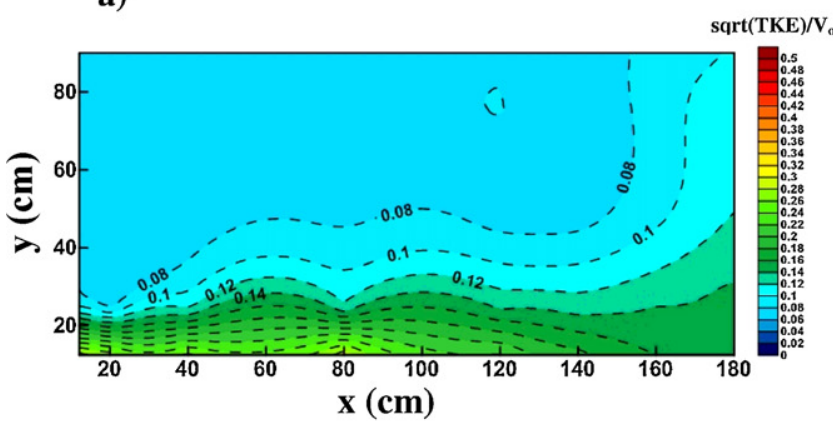

c)

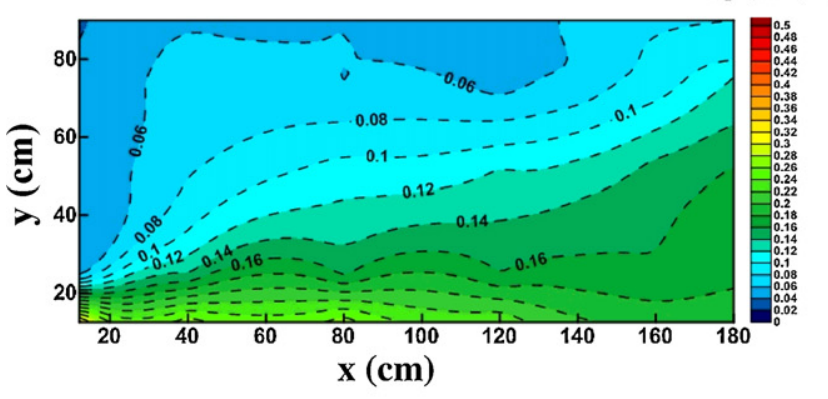

e)

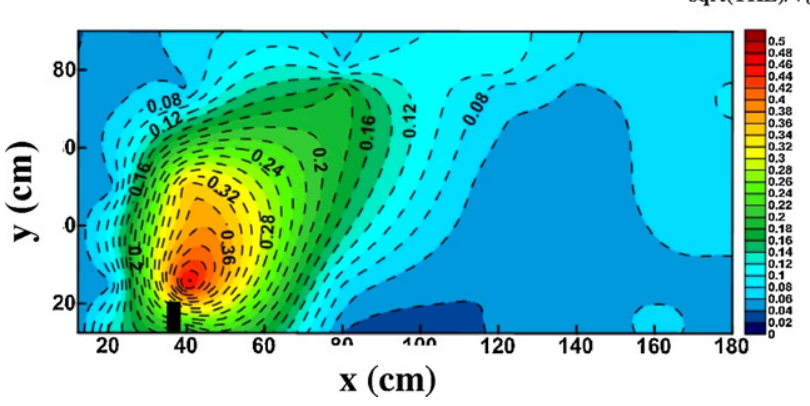

b)

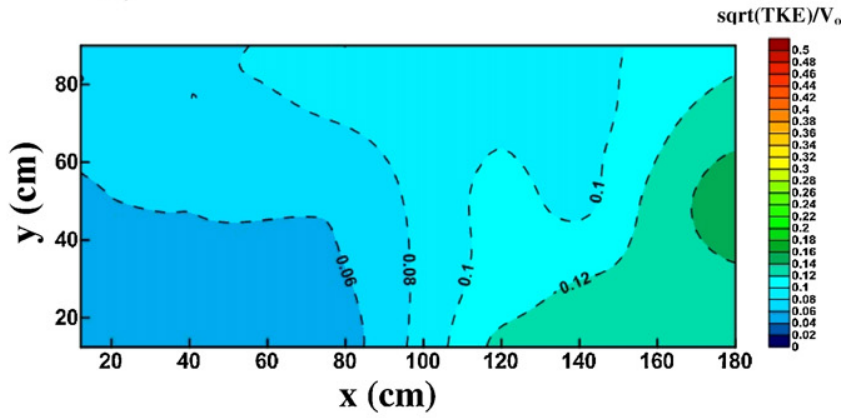

d)

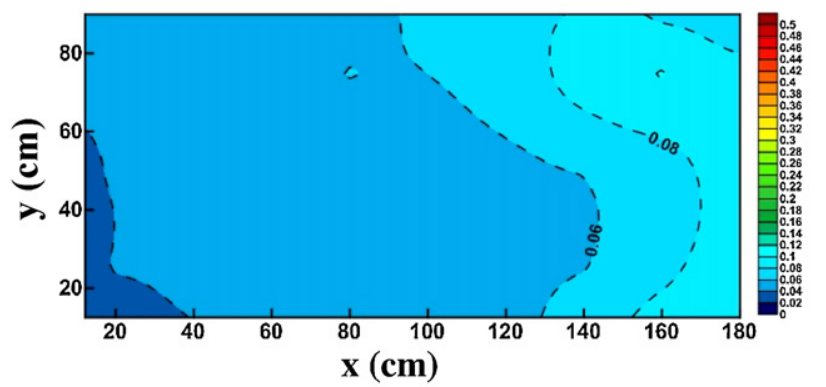

f)

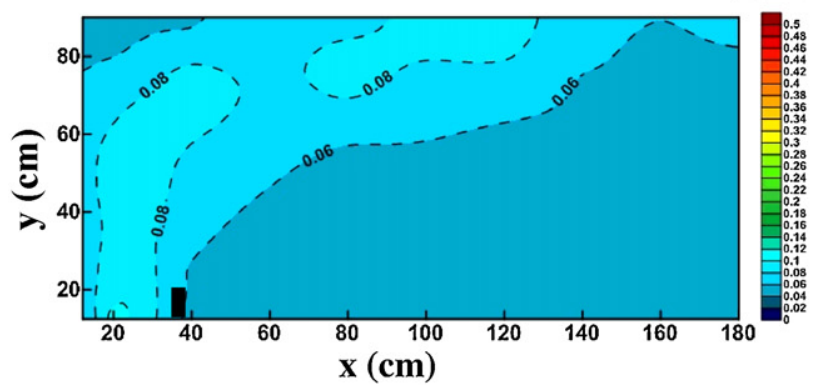

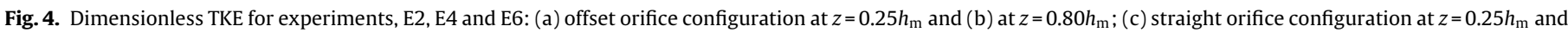
(d) at $z=0.80 h_{\mathrm{m}}$; (e) straight orifice with a bar configuration at $z=0.25 h_{\mathrm{m}}$ and (f) at $z=0.80 h_{\mathrm{m}}$. Flow from the orifice enters at the bottom left of the diagram.

orifices, leading to longer transit times (mean $\pm \mathrm{SE}$ (min): $13.2 \pm 4.61$ ) compared to offset orifices (mean \pm SE (min): $7.78 \pm 1.36)$ and straight orifices with a deflector bar (mean \pm SE (min): $6.18 \pm 2.13$ ). Nevertheless, no significant differences on the time of passage of small fish were found among configurations (Kruskal-Wallis ANOVA: $P=0.093$ ). In contrast, the time taken by larger fish to successfully ascend the fishway was strongly dependent on the tested configuration (Kruskal-Wallis ANOVA: $P=0.005$ ). Indeed, larger fish took much longer to ascend the fishway in experiments with straight orifices and a bar (mean $\pm \mathrm{SE}$ ( $\mathrm{min}): 12.66 \pm 6.06$ ) than with offset (mean $\pm \mathrm{SE}(\mathrm{min}): 6.55 \pm 0.94)$ or straight orifices (mean \pm SE ( $\min ): 3.33 \pm 0.84$ ). Size-related differences were also found in experiments with straight orifices with a deflector bar (Fig. 7b), where smaller fish clearly took less time to ascend the fishway (Mann-Whitney $U$-test: $Z=2.33, P=0.019$ ).

\subsubsection{Fish swimming behaviour responses to turbulent flow} kinematics

In all the experiments, fish were found to prefer areas of lower turbulence as evident by the highest \% of time [(transit times/total time in the pool) $\times 100$ ] spend by fish in each flow region. Both size classes spent the following \% time in region B of each orifice arrangement: offset (small fish: 78\%; large fish: 71\%); straight (small fish: 87\%; large fish: 92\%). In contrast, respective $\%$ times spent in region A were: offset (small fish: $22 \%$; large fish: $29 \%$ ); straight (small fish 13\%; large fish: $8 \%$ ). Although less evident, such trend was also observed in the straight orifice with a deflector bar arrangement, as shown by the \% times spent in region B (small fish: 9\%; large fish: 6\%) and C (small fish: 63\%; large fish: 48\%) compared to those spent in region A (small fish: $28 \%$; large fish: $47 \%$ ). The effect of hydraulics on fish swimming behaviour was determined based on the correlations established among transit times of fish in each cell of the pool and the respective hydraulic kinematic conditions (Table 3 ). Since fish movements preferentially occurred near the bottom of the flume, previous analyses (Silva et al., 2011, 2010) included hydraulic conditions only at $z=0.25 h_{\mathrm{m}}$. Configuration-related patterns between fish transit time and hydraulics were found for species size-classes. In experiments conducted with offset orifices, fish behaviour for both size-classes seemed to be influenced by hydraulic conditions, particularly TI, TKE and Reynolds shear stress. Swimming behaviour of smaller fish appeared to be strongly influenced by these variables (Table 3). Under the high velocities and turbulence levels created by the straight orifice arrangement, smaller fish were observed to lose 
a)

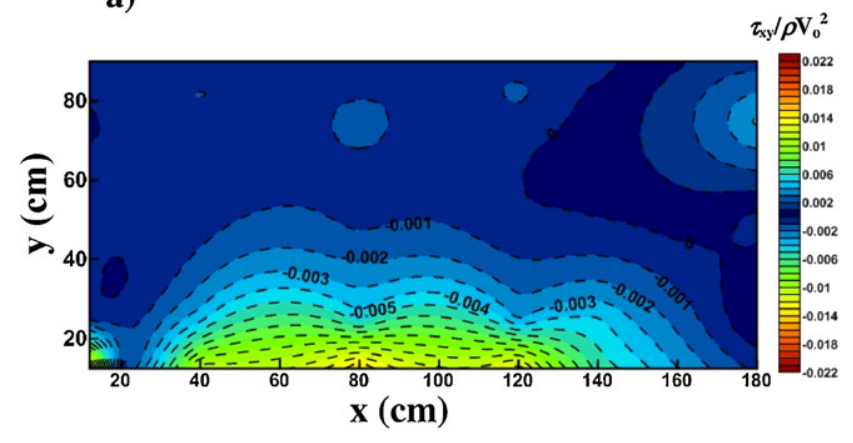

c)

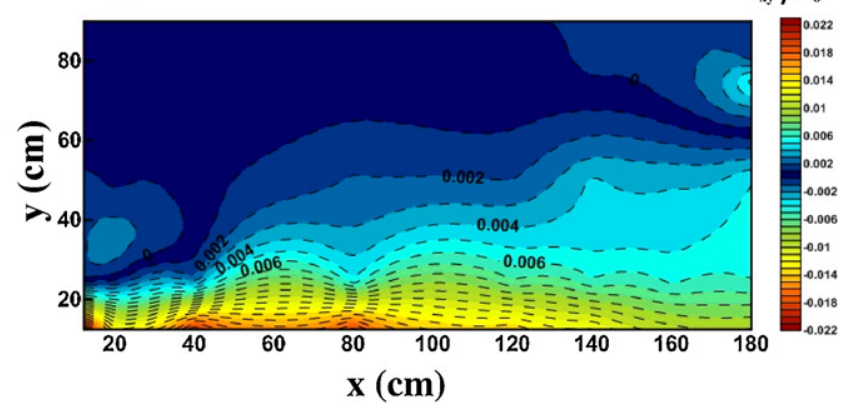

e)

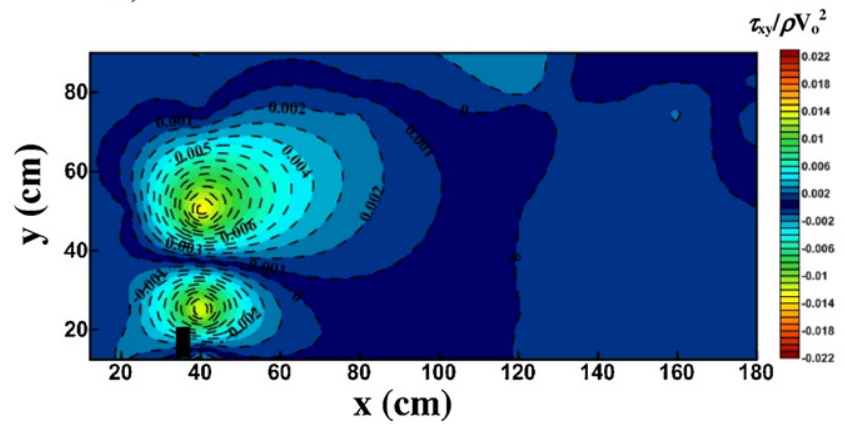

b)

$\tau_{\mathrm{s}} / \rho \mathrm{V}_{\mathrm{o}}{ }^{2}$

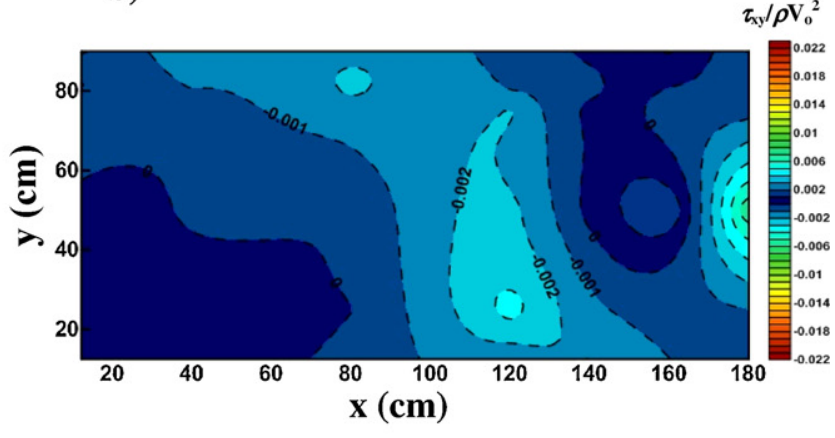

d)

$\tau_{\mathrm{y}} / \rho \mathbf{V}_{\mathrm{o}}^{2}$

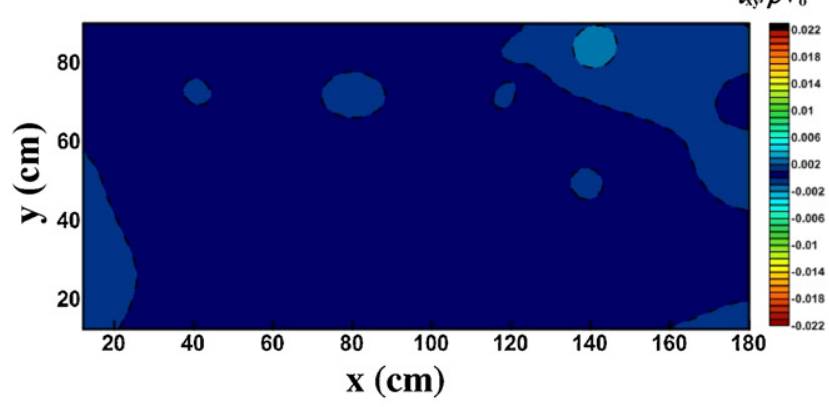

f)

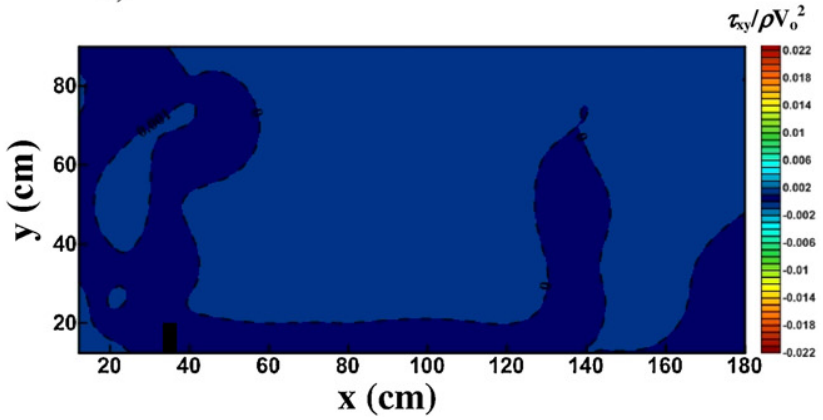

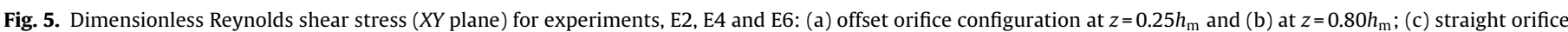

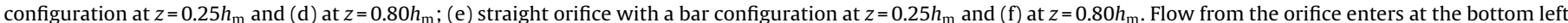
of the diagram.

Table 3

Spearman rank test results obtained to test for possible correlations between the transit time of fish in each cell and hydraulics.

\begin{tabular}{|c|c|c|c|c|c|}
\hline Configuration & Fish size-class & Dependent variable & $N$ & Spearman rank $\mathrm{r}$ & $P$-value \\
\hline \multirow[t]{4}{*}{ Offset orifices } & \multirow[t]{3}{*}{ Smaller fish } & $\operatorname{TKE}\left(\mathrm{m}^{2} / \mathrm{s}^{2}\right)$ & 20 & -0.42 & $0.003^{* *}$ \\
\hline & & $\left|-\rho \overline{u^{\prime} v^{\prime}}\right|\left(\mathrm{N} / \mathrm{m}^{2}\right)$ & 20 & -0.43 & $0.003^{* *}$ \\
\hline & & $\mathrm{TI}$ & 20 & -0.45 & $0.001^{* *}$ \\
\hline & Larger fish & $\left|-\rho \overline{u^{\prime} v^{\prime}}\right|\left(\mathrm{N} / \mathrm{m}^{2}\right)$ & 20 & -0.33 & $0.025^{*}$ \\
\hline Straight orifices & Larger fish & $\left|-\rho \overline{u^{\prime} v^{\prime}}\right|\left(\mathrm{N} / \mathrm{m}^{2}\right)$ & 20 & 0.37 & $0.039^{*}$ \\
\hline \multirow{3}{*}{$\begin{array}{l}\text { Straight + bar } \\
\text { orifices }\end{array}$} & Smaller fish & $\left|-\rho \overline{u^{\prime} v^{\prime}}\right|\left(\mathrm{N} / \mathrm{m}^{2}\right)$ & 20 & 0.52 & $0.002^{* *}$ \\
\hline & \multirow[t]{2}{*}{ Larger fish } & $v(\mathrm{~m} / \mathrm{s})$ & 20 & -0.38 & $0.034^{*}$ \\
\hline & & $\left|-\rho \overline{u^{\prime} v^{\prime}}\right|\left(\mathrm{N} / \mathrm{m}^{2}\right)$ & 20 & 0.4 & $0.026^{*}$ \\
\hline
\end{tabular}

Four different factors were analyzed (velocity, TKE, Reynolds shear stress and TI) but only those with significant values $(P<0.05$, Zar, 1996$)$ are shown.

${ }^{*} P<0.05$

${ }^{* *} P<0.01$

${ }^{* * *} P<0.001$

their capacity to hold position, drifting and being displaced to the downstream adjacent pool, so no relation between transit time of smaller fish and the existing hydraulic conditions was found for this experimental design. In contrast, behaviour of larger fish appeared to be significantly influenced by Reynolds shear stress (Spearman rank correlation: $r=0.37, P=0.039$ ) (Table 3 ). This hydraulic parameter was also correlated with fish transit time for both size-classes in experiments with straight orifices and a deflector bar (Spearman 
a)

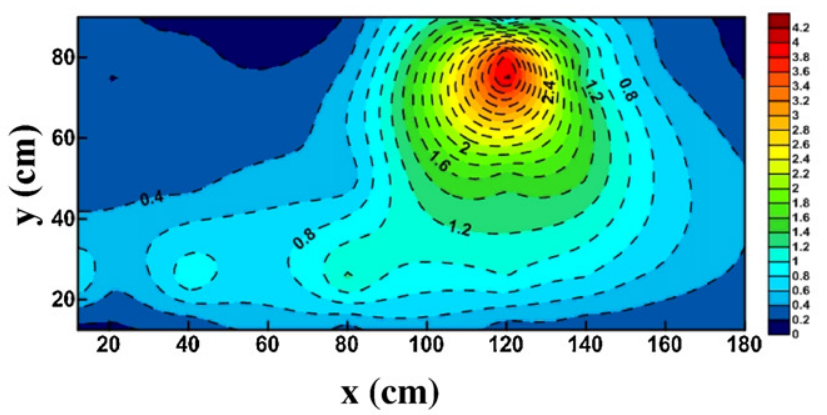

c)

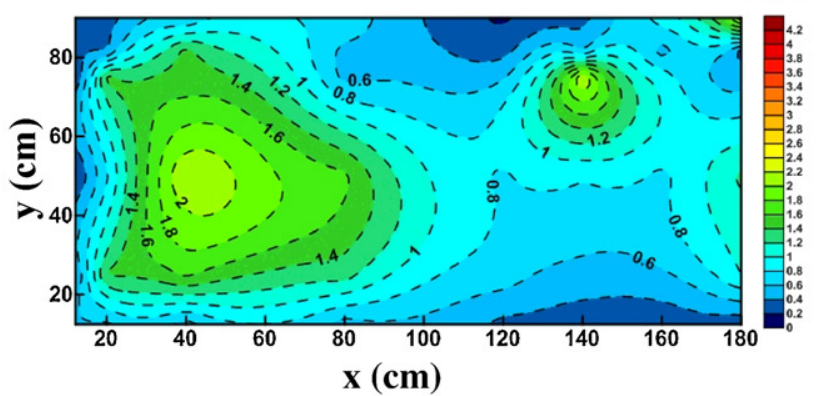

e)

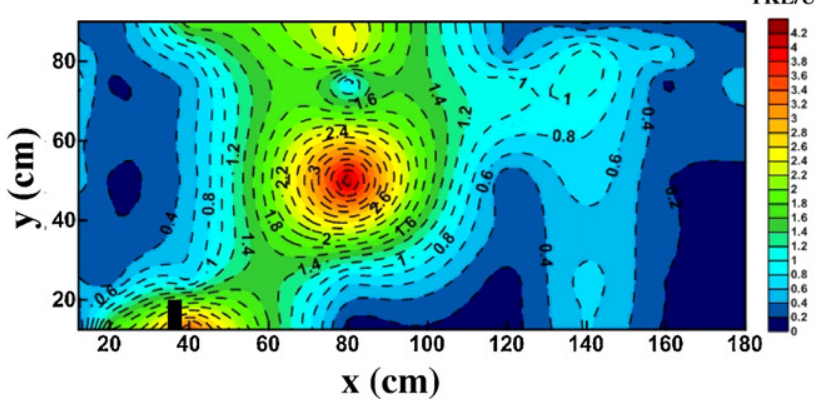

b)

TKE/U ${ }^{2}$

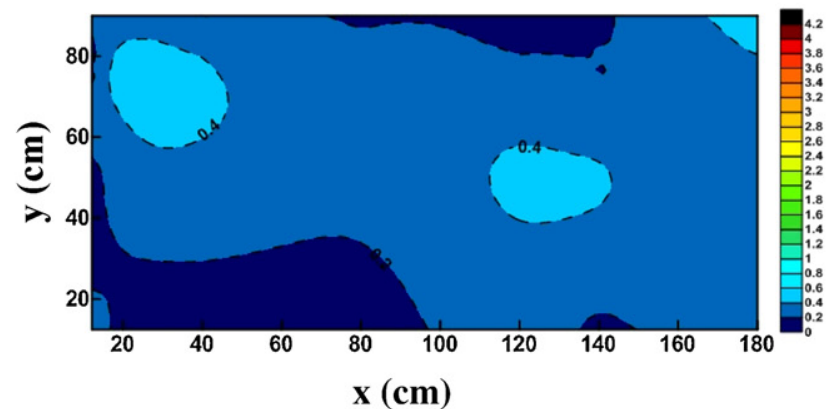

d)

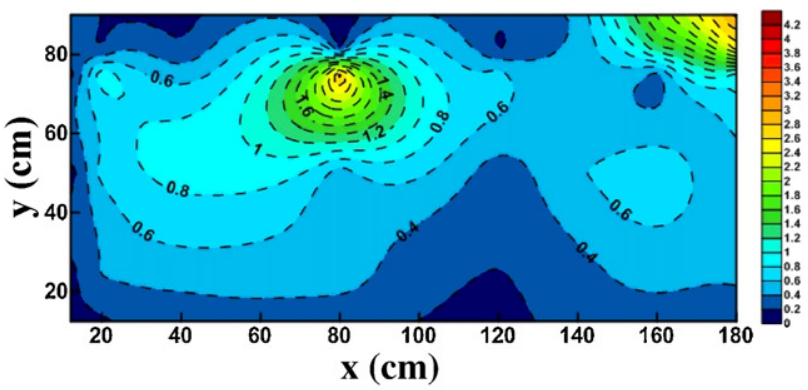

f)

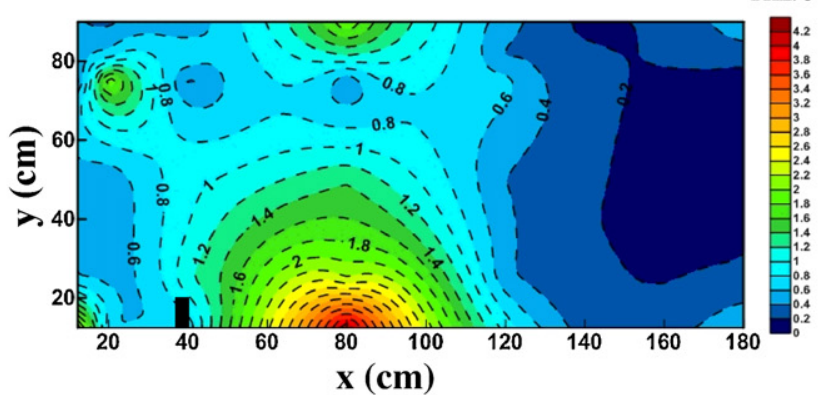

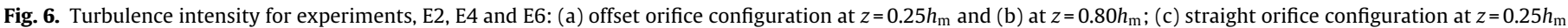
and (d) at $z=0.80 h_{\mathrm{m}}$; (e) straight orifice with a bar configuration at $z=0.25 h_{\mathrm{m}}$ and (f) at $z=0.80 h_{\mathrm{m}}$. Flow from the orifice enters at the bottom left of the diagram.

Table 4

Variables entered in model of forward stepwise regression analysis explaining fish's transit time of both size-classes in the tested designs.

\begin{tabular}{|c|c|c|c|c|}
\hline Design & Variable & F-test & $r^{2}$ & $D$ \\
\hline \multicolumn{5}{|l|}{ Offset orifices } \\
\hline \multirow[t]{3}{*}{ Smaller fish } & & & & 1.86 \\
\hline & $\mathrm{TI}$ & $7.77^{* *}$ & 0.15 & \\
\hline & $\left|-\rho \overline{u^{\prime} v^{\prime}}\right|$ & $4.96^{*}$ & 0.24 & \\
\hline \multirow[t]{2}{*}{ Larger fish } & & & & 1.43 \\
\hline & $\left|-\rho \overline{u^{\prime} v^{\prime}}\right|$ & $4.66^{*}$ & 0.09 & \\
\hline \multicolumn{5}{|l|}{ Straight orifices } \\
\hline \multirow[t]{2}{*}{ Larger fish } & & & & 1.25 \\
\hline & $\left|-\rho \overline{u^{\prime} v^{\prime}}\right|$ & $7.06^{*}$ & 0.2 & \\
\hline
\end{tabular}

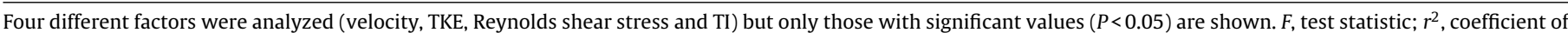
determination; $D$, Durbin-Watson statistics.

${ }^{*} P<0.05$.

${ }^{* *} P<0.01$.

${ }^{* * *} P<0.001$.

rank correlation: small fish, $r=0.52, P=0.002$; large fish, $r=0.40$, $P=0.026$ ). This suggests that in all experimental designs, Reynolds shear stress may have been the most influential hydraulic variable on fish behaviour. Indeed, from the hydraulic variables considered, this was the most important parameter with the most significant results in explaining variation in fish transit time(Table 4). Whereas both Reynolds shear stress and TI explained $39 \%$ of the variation in transit time for smaller fish in experiments with offset orifices, Reynolds shear stress was the only factor significantly correlated with transit time for larger fish in experiments with offset (9\%) 


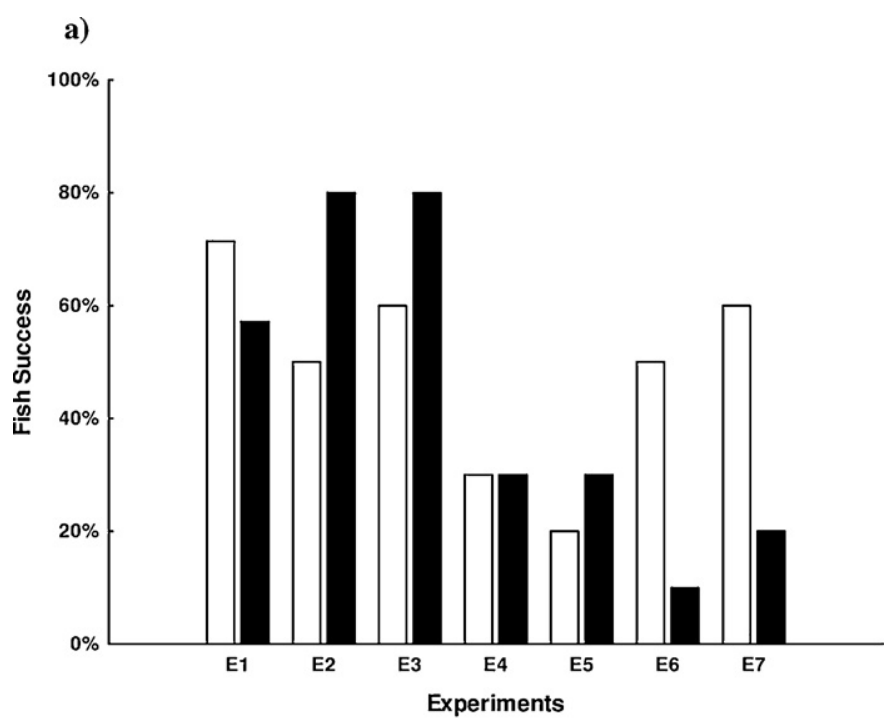

b)

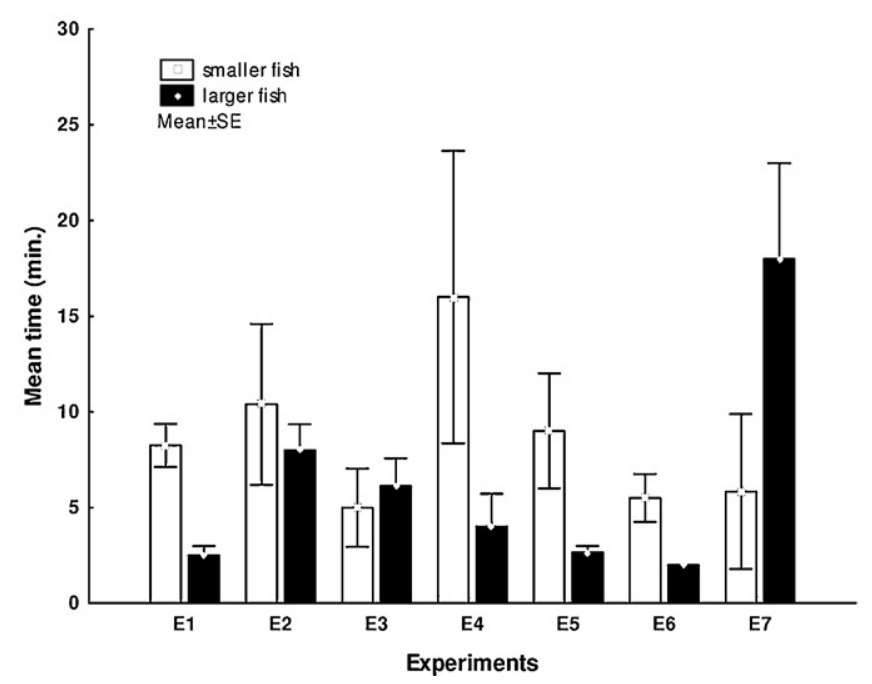

Fig. 7. (a) Fish passage success (\%); (b) mean successful passage time (mean \pm standard error) ( $\mathrm{min}$ ) for small adults $(15 \leq \mathrm{TL}<25 \mathrm{~cm}$ ) and large adults $(25 \leq \mathrm{TL}<35 \mathrm{~cm})$; barbel across all experiments. Offset orifices (E1, E2, E3), straight orifices (E4 and E5) and straight orifices with a bar (E6 and E7).

and straight orifices (20\%). There was no significant autocorrelation $(0.52<D<2.01, \alpha=0.05)$ in the residuals of each regression (Table 4).

\subsubsection{Fish response to eddy size}

The ratio between maximum longitudinal $\left(\mathrm{Le}_{\Delta x}\right)$ and transversal $\left(\operatorname{Le}_{\Delta y}\right)$ horizontal eddy diameters and the total length of the fish tested (TL) is plotted in Fig. 8. The distribution of eddy sizes was negatively skewed, with a higher number of larger eddies and few small eddies, particularly in experiments with offset and straight orifices (Fig. 3 and Table 5). Under these two experimental conditions the size of the created eddies, in most cases, was higher than fish length for both fish-sizes ( $\mathrm{Le}_{\Delta x} / \mathrm{TL}>1$ and $\mathrm{Le}_{\Delta y} / \mathrm{TL}>1$ ) (Fig. 8a and $b$ ). In the straight orifice arrangement, smaller fish were found to drift towards the main flow and been dragged to the immediately downstream pool. In contrast, the larger fish, which have a higher swimming capacity than the smaller ones (Silva et al., 2011), were able to re-establish their orientation and successfully ascend the fishway. Nevertheless, under the straight orifice arrangement,

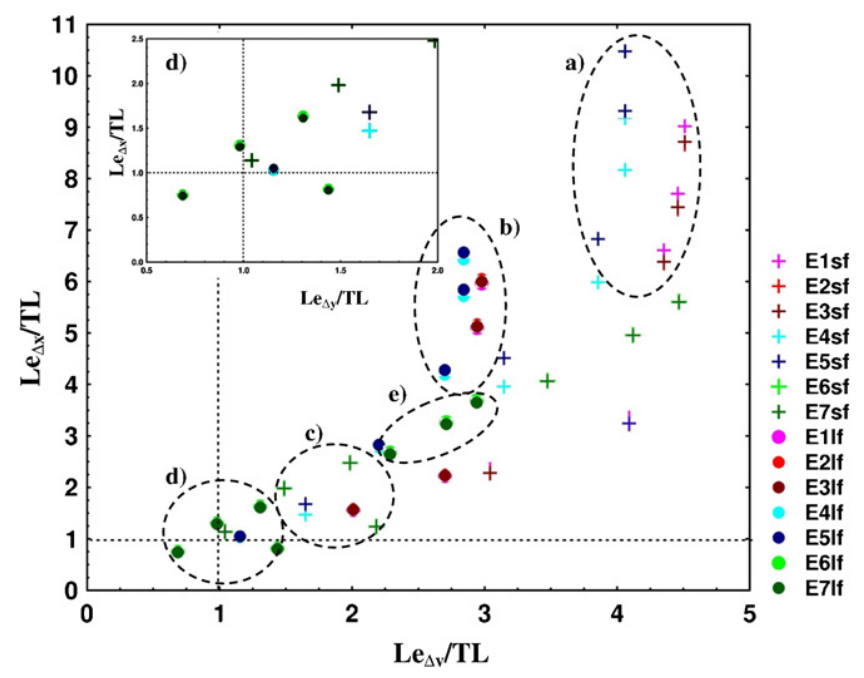

Fig. 8. Relation between maximum longitudinal $\left(\mathrm{Le}_{\Delta x}\right)$ and transversal $\left(\mathrm{Le}_{\Delta y}\right)$ diameters of the eddy and the total length of the fish (TL) for small $\left(\mathrm{TL}_{\mathrm{sf}}\right)(+)$ and large fish $\left(\mathrm{TL}_{\mathrm{lf}}\right)(\bigcirc)$ in offset orifices (in red), straight orifices (in blue) and straight orifices with a bar (in green). (For interpretation of the references to colour in this figure legend, the reader is referred to the web version of this article.)

some larger specimens were not able to recover their orientation in the pool and subsequently fell back downstream. In experiments conducted with straight orifices with a deflector bar, where a wider range of eddies with different sizes was created (Fig. 3 and Table 5), fish swimming behaviour was likely affected more by these hydraulic structures. Herein, strong size-related differences on swimming behavioural responses to eddy size were observed between smaller and larger fish. When facing eddies larger than their size $\left(\mathrm{Le}_{\Delta x} / \mathrm{TL}_{\mathrm{sf}}>1\right.$ and $\mathrm{Le}_{\Delta y} / \mathrm{TL}_{\mathrm{sf}}>1$ ) (Fig. 8c), smaller fish were observed to display one of two behaviours: (a) swim steadily through the eddies, exhibiting a swim behaviour characterized by larger lateral body amplitudes and curvatures than swimming in areas with very high velocities (main flow region); (b) become disorientated but rapidly adjust their body stability and finding their route to successfully ascend the fishway. Some of the eddies generated were of similar size to the size of the larger fish $\left(\mathrm{Le}_{\Delta x} / \mathrm{TL}_{\mathrm{lf}} \approx 1\right.$ and $\mathrm{Le}_{\Delta y} / \mathrm{TL}_{\mathrm{lf}} \approx 1$ ) (Table 5 and Fig. 8d). Under such conditions fish were seen to spread their pectoral fins in an attempt to stabilize their body position. These responses increased the hydraulic resistance of their body, thereby decreasing fish swimming performance. This is evident from the longer transit times estimated to ascend the fishway when straight orifices with a deflector bar were used, compared to shorter transit times when straight or offset orifice arrangements were employed (Fig. 7b). Nevertheless, most of the fish were dragged to the downstream pool as a result of the high magnitudes of the forces acting on their body and the respective energy costs associated to restore stability. In areas with eddy size smaller than fish length $\left(\mathrm{Le}_{\Delta x} / \mathrm{TL}_{\mathrm{lf}}<1\right.$ and $\mathrm{Le}_{\Delta y} / \mathrm{TL}_{\mathrm{lf}}<1$; region $\mathrm{B}$ in Fig. 8d), larger fish were observed to swim steadily through eddies towards the upstream orifice. When facing areas with eddies bigger than their size $\left(\mathrm{Le}_{\Delta x} / \mathrm{TL}_{\mathrm{lf}}>1\right.$ and $\mathrm{Le}_{\Delta y} / \mathrm{TL}_{\mathrm{lf}}>1$; Fig. 8e), some larger fish got disorientated and fell back to the downstream pool, while others were found to recover their route and successfully move forward.

\section{Discussion}

This study focused on the analysis of the effects of hydrodynamic turbulent flow kinematics on the swimming behaviour of Iberian barbel under different turbulence conditions. These 
Table 5

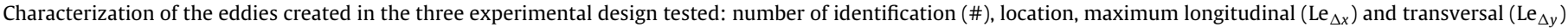
diameters and area $\left(a_{\mathrm{e}}\right)$ of the eddy. Ratio between longitudinal and transversal diameter and smaller $\left(\mathrm{TL}_{\mathrm{sf}}\right)$ and larger fish $\left(\mathrm{TL}_{\mathrm{lf}}\right)$ total length.

\begin{tabular}{|c|c|c|c|c|c|c|c|}
\hline Design & $\#$ & Zone & $\mathrm{Le}_{\Delta x}(\mathrm{~m})$ & $\operatorname{Le}_{\Delta y}(\mathrm{~m})$ & $a_{\mathrm{e}}\left(\mathrm{m}^{2}\right)$ & Smaller fish (sf) & Larger fish (lf) \\
\hline \multirow[t]{5}{*}{ Offset orifices } & 1 & Region B & 0.45 & 0.58 & 0.82 & $\mathrm{Le}_{\Delta y} / \mathrm{TL}_{\mathrm{sf}}>1$ & $\mathrm{Le}_{\Delta y} / \mathrm{TL}_{\mathrm{lf}}>1$ \\
\hline & 2 & Region B & 0.64 & 0.78 & 1.57 & $\mathrm{Le}_{\Delta x} / \mathrm{TL}_{\mathrm{sf}}>1$ & $\mathrm{Le}_{\Delta x} / \mathrm{TL}_{\mathrm{lf}}>1$ \\
\hline & 3 & Region B & 1.26 & 0.83 & 3.28 & & \\
\hline & 4 & Region B & 1.47 & 0.85 & 3.92 & & \\
\hline & 5 & Region B & 1.72 & 0.86 & 4.64 & & \\
\hline \multirow[t]{5}{*}{ Straight orifices } & 1 & Region B & 0.29 & 0.33 & 0.30 & $\mathrm{Le}_{\Delta y} / \mathrm{TL}_{\mathrm{sf}}>1$ & $\mathrm{Le}_{\Delta y} / \mathrm{TL}_{\mathrm{lf}}>1$ \\
\hline & 2 & Region B & 0.78 & 0.62 & 1.52 & $\mathrm{Le}_{\Delta x} / \mathrm{TL}_{\mathrm{sf}}>1$ & $\mathrm{Le}_{\Delta x} / \mathrm{TL}_{\mathrm{lf}}>1$ \\
\hline & 3 & Region B & 1.18 & 0.76 & 2.82 & & \\
\hline & 4 & Region B & 1.61 & 0.80 & 4.04 & & \\
\hline & 5 & Region B & 1.81 & 0.80 & 4.55 & & \\
\hline \multirow{7}{*}{$\begin{array}{l}\text { Straight orifices } \\
\text { with a bar }\end{array}$} & 1 & Region B & 0.23 & 0.21 & 0.15 & $\mathrm{Le}_{\Delta y} / \mathrm{TL}_{\mathrm{sf}}>1$ & $1<\mathrm{Le}_{\Delta y} / \mathrm{TL}_{\mathrm{lf}} \leq 1$ \\
\hline & 2 & Region B & 0.25 & 0.44 & 0.35 & $\mathrm{Le}_{\Delta x} / \mathrm{TL}_{\mathrm{sf}}>1$ & $1<\mathrm{Le}_{\Delta x} / \mathrm{TL}_{\mathrm{lf}} \leq 1$ \\
\hline & 3 & Region A & 0.50 & 0.40 & 0.63 & & \\
\hline & 4 & Region A & 0.82 & 0.70 & 1.80 & & \\
\hline & 5 & Region A & 1.00 & 0.83 & 2.61 & & \\
\hline & 6 & Region A & 1.13 & 0.90 & 3.19 & & \\
\hline & 7 & Region C & 0.40 & 0.30 & 0.38 & & \\
\hline
\end{tabular}

turbulent conditions were generated by the three different orifice arrangements (offset, straight and straight orifices with a deflector bar) in a full scale experimental pool-type fishway. Fish performance within the fishway was similar to the behaviour commonly displayed by this species under natural conditions, as fish moved primarily near the bottom of the flume $\left(z=0.25 h_{\mathrm{m}}\right)$. This is typical behaviour exhibited by this species when moving freely and volitionally in its natural habitat, as a result of vertical segregation associated with trophic (bottom feeders) and reproductive adaptations (epi-benthic fish, i.e. fish that spawn in gravel beds) (Collares-Pereira et al., 1995; Martínez-Capel and García de Jalón, 1999). Furthermore, the highest passage success and the corresponding lower transit times observed in experiments with the offset orifice arrangement occurred under velocities commonly encountered by Iberian barbel when exploring for feeding and spawning purposes (Martínez-Capel et al., 2009). This fits well with the physiological strategy of this species to minimize energy expenditure in maintaining position in the water column because of their limited swimming ability (Doadrio, 2001). Likewise, the strong trend by fish to avoid areas of high turbulence levels was demonstrated by the high negative correlations found between the transit time of fish in each cell and the respective values of TKE, Reynolds shear stress and TI in all the experimental configurations tested. Avoiding high turbulence is a behaviour commonly observed with this and many other fish species and emerges as an attempt to minimize energy expenditure to sustain stability.

The behavioural response of fish to the hydrodynamic heterogeneity of flows in aquatic systems, such as turbulence resulting from the interactions of gravity and wind-driven currents in water-air and water-water interfaces, as well as water moving past physical structures (Webb, 2004), strongly depends on the spatial and temporal perturbation magnitude of the forces acting on the fish, the time of fish exposure, species, life stage and individual size (Lupandin, 2005; Cotel et al., 2006). Results from the present study attest to this relationship, as Reynolds shear stress was the main factor among all the hydraulic variables analyzed, which explained passage success and fish transit times in experiments with offset and straight orifice arrangements. Shear stress levels that are low enough to avoid injury may still lead to fish disorientation and/or displacement, as a result of the overlap of drag to thrust forces and the high energy expenditure required to generate thrust (Odeh et al., 2002; Silva et al., 2011). Odeh et al. (2002) determined that rainbow trout (Onchorhynchus mykiss), Atlantic salmon (S. salar) and hybrid bass (Morone saxatilis $\times$ Morone chrysops), exposed to levels of Reynolds shear stress above $50 \mathrm{~N} / \mathrm{m}^{2}$ for a period of $10 \mathrm{~min}$ may suffer injuries but not mortality. Cada et al. (1999) report shear stress values $\geq 700 \mathrm{~N} / \mathrm{m}^{2}$ cause injuries or mortalities in fish. In the present experiments Reynolds shear stress values varied from $0.02 \mathrm{~N} / \mathrm{m}^{2}$ to $73.4 \mathrm{~N} / \mathrm{m}^{2}$. As expected fish damage was not witnessed but fish disorientation and displacement was observed.

Although the effects of single turbulence descriptors (TI, TKE, or Reynolds shear stress) have been studied (Odeh et al., 2002; Silva et al., 2011), these may yield only partial effects on the swimming capacity and behaviour of fish. Consideration of other or multiple turbulence descriptors may provide a more thorough understanding of the effects of hydrodynamics on fish behaviour and movements. The behaviour of fish in experiments conducted with straight orifices with a bar clearly attests to this concept, as none of the above listed single descriptors appeared to explain fish behaviour in this experimental design, pointing towards additional hydraulic mechanisms. In fact, when swimming in turbulent flows, fish are exposed to a complex system of forces acting upon their body that can cause translational and/or rotational displacements (Tritico and Cotel, 2010; Liao, 2007). This may result from the action of typical vortical structures created in turbulent flows that are known to play a significant role in fluid flow phenomena as momentum, mass and heat transfer (Pope, 2000). Thus, the high levels of turbulence found in the offset with a bar experimental setup (see Section 3.1.2), led to the hypothesis that the distribution of eddy sizes could be the primary turbulent variable affecting fish swimming behaviour.

As the entire length of the eddy approaches the fish width for horizontal eddies or the fish depth for vertical eddies (Tritico and Cotel, 2010), there is a robust correlation between fish size and turbulence scale, as clearly evident through the size-related behavioural differences found in the three experimental configurations where fish faced eddies of different size. If an eddy is larger than the total length of a fish, its balance should not be affected, although fish may experience disorientation and even displacement (Lupandin, 2005; Tritico and Cotel, 2010; Webb and Cotel, 2010), as observed in fish of both size-classes in experiments conducted with offset and straight orifices. Nevertheless, if an eddy size is much larger than fish total length, fish orientation might not be disturbed, as observed in some small fish in experiments with straight orifices with a bar. In addition, when facing eddies smaller than their size, fish may swim steadily through them (Liao, 2007). This behaviour is a complex phenomenon that results from the capacity of the fish to integrate biomechanics and sensory 
processes. Such ability allows fish to explore turbulent areas and greatly enhance propulsive efficiency by extracting energy from eddies, thus decreasing the energy expenditure required to generate thrust (Liao, 2007). This interesting capacity of animals to reduce locomotory energy costs is well known in soaring migratory birds (Hedenström, 1993) and insects (Ristroph et al., 2011) which use the energy of air currents to propel them in turbulent air. The same strategy is used by fish while swimming in turbulent flow, which might explain the behaviour exhibited by larger fish while steadily swimming through smaller eddies in experiments involving straight orifices with a bar. In contrast, both stability and swimming performance of fish are known to be strongly affected by eddy kinematics of size similar to their body length (Tritico and Cotel, 2010).

It is known that fish ability to hold position results from their faculty to generate enough thrust to balance drag forces (Webb, 1988), which implies a complex interplay between biomechanic and physiological processes. Several authors have pointed to fin activity as one of the main mechanisms that permits fish to maintain stability in complex flows (Bioly and Magnan, 2002; Webb and Cotel, 2010). Pectoral fins can be particularly effective and their movements can vary widely during swimming in turbulent flows (Liao, 2007). The observed spread of the pectoral fins of larger fish, in areas with eddies of similar size to their body length in experiments conducted with straight orifices with a deflector bar, clearly illustrated that fins provide an important mechanism for fish to self-correct and re-establish stability during swimming and manoeuvring (Webb and Cotel, 2010). This behaviour is usually associated with a decrease in fish swimming performance from an increase in hydraulic resistance (Tritico and Cotel, 2010), which may explain the higher passage times found for larger fish in this experimental design. Under such hydraulic conditions fish can also experience angular rotations of their body, which strongly depend on eddy orientation (vertical or horizontal), and is commonly associated to an increase in oxygen consumption (Tritico and Cotel, 2010) which also decreases fish swimming performance. It is postulated that the effects of eddy orientation on fish vary according to species morphology and locomotion (Liao, 2007; Tritico and Cotel, 2010; Webb and Cotel, 2010). It is also believed that horizontal eddies might induce stronger impacts on fish swimming capacity when compared to vertical eddies, as demonstrated by Tritico and Cotel (2010). The stabilizing control system of fish would be better suited for countering yawing rather than pitching perturbations (Weihs, 2002; Webb, 2006).

In the present research, it is clear that in certain circumstances, turbulence may be deemed a feature of hydrodynamic environments that is a benefit rather than a constraint. Furthermore, it was observed that fish had a tendency to preferentially explore areas of low levels of turbulence and were clearly able to detect specific ranges of turbulence. This reveals, not surprisingly, that they can be quite sensitive to turbulent cues (Pavlov et al., 2000; Liao, 2007), which can influence fish behavioural routines and habitat choices (Webb, 2002). The effects of complex unsteady flows on fish swimming performance and behaviour has recently been investigated (Triantafyllou et al., 2002; Liao et al., 2003; Smith and Brannon, 2005). Yet, there is a strong gap between the spatial and temporal resolution of flows at which hydraulics are modelled and at which fish respond (Liao, 2007; Webb and Cotel, 2010). Although, hydrodynamics has a long history and is a wellstudied subject (Tennekes and Lumley, 1972; Pope, 2000; Shah and Tachie, 2009), the nature and characterization of turbulent flow structures is still lacking. Thus, there is a critical need to comprehend and evaluate the hydrodynamic features of turbulent flows that will lead to a better understanding on how turbulence might impact the fish's swimming capacity and behaviour. The use of physical models and advanced hydrometric systems, as well as computational fluid dynamics (CFD) are needed to allow a more comprehensive understanding of physical phenomena, as well as predict and analyze the levels of turbulence in unsteady flows. Equally, technological advancements that allow fish observation and real-time measurements of physiological costs of swimming are necessary to understand the biological influence of turbulent flows on fish behaviour. Electromyogram (EMG) studies, which have been shown to adequately monitor the physiological swimming effort of fish (Mateus et al., 2008), associated with underwater video verification of swimming kinematics, may help to identify fish preference/response to different levels and structures of turbulence. Thus, research correlating measurements of flow kinematics and analyses of the vortical turbulent structures (eddy size, strength, orientation and vorticity) with metabolic swimming costs, to better understand the impact of turbulence on fish behaviour is needed. To date, data from studies conducted in laboratory settings have conclusively contributed to improved understanding between flow hydrodynamics and fish swimming behaviour, stressing the accuracy of such research efforts. As is evident from this study, similarity exists between fish behaviour observed in experiments and under commonly found natural conditions for the same species. Hence, comprehensive ecohydraulic laboratory studies which include both fish observations and hydrodynamics, where confounding variables are possible to control and manipulate, are likely to be a good approach to increase knowledge in this area.

The results show that station holding, ability to maintain posture, and swimming behaviour are strongly affected by turbulence, particularly by Reynolds shear stress and the presence of turbulent eddies in close proximity to fish. Although biological testing is needed and experiments are underway, strategically placed and properly sized artificial elements, such as blocks, hemispheres or cylinders (Shamloo et al., 2001; Katopodis, 2002) within a fishway may generate favourable hydraulic conditions, including appropriate levels of shear stress, as well as eddy orientation and size. The placement of more natural substrates may also improve migration opportunities for different species in fishways or river restoration projects. Such substrates would be expected to generate more nature-like areas of different levels of turbulence, as well as eddy sizes and orientations, which fish may use to volitionally migrate over a range of hydraulic conditions. These conditions may allow fish to minimize swimming energetic costs by either taking advantage of the energy associated with eddies for propulsion or using areas of low turbulence to rest. Furthermore, adding artificial or more natural substrates may be a very low cost alternative, with low maintenance requirements, as long as it is secured from washing-out. The findings of this study are believed to provide valuable insights on swimming behavioural responses of epi-benthic cyprinids to the hydrodynamic kinematics and vortical structures of turbulent flows. Nevertheless, the effects of turbulence on fish swimming behaviour were shown to be important, thus accurate knowledge of its effects on different fish species is essential to improve future fishway and stream restoration projects.

\section{Conclusions}

The influence of turbulence and flow kinematics on the swimming behaviour of a potamodromous cyprinid was studied in a laboratory ecohydraulic flume. Fish responses were observed and associated with turbulence variables created in a pool-type fishway by three orifice arrangements (offset, straight and straight orifices with a deflector bar). Flow topology (patterns and eddies) 
and flow kinematics (velocity, turbulent kinetic energy, Reynolds shear stress and turbulence intensity) were characterized using a 3D ADV and the consequent responses on swimming behaviour and upstream movements of Iberial barbel of two different size-classes were analyzed. Although size-related fish behavioural responses to hydraulics were found, Reynolds shear stress and eddy size appeared as the main factors explaining fish swimming behaviour. Fish were found to avoid areas of high Reynolds shear stress and when facing eddies of similar size to their total length, experienced disorientation and loss of stability, leading to high levels of energy expenditure, low rates of passage success and longer transit times. The results show that Reynolds shear stress and eddy size both of which are strongly dependent on fishway pool geometric features, could be a barrier for upstream fish migration. Minimizing fish disorientation and loss of stability attributed to eddies may increase fish passage success, efficiency and shorten transit times. Of the three orifice arrangements, the offset configuration controlled Reynolds shear stress and eddy size best, producing the most favourable hydraulic conditions, and was the most efficient for passage of both sizes of barbel. Introducing a bar on the side of the pool had a positive effect on passage of smaller barbel but a negative effect on the larger ones. A better understanding of the relationship between fish swimming behaviour and hydraulic conditions could result from the ability to measure and accurately model turbulence, improving both spatial and temporal resolution at which hydraulics are analyzed and at which fish are observed to respond. Computer models could be a good approach to more faithfully reproduce different flow conditions and predict levels of turbulence. Nonetheless, such models should first be verified to ensure their capability and accuracy. Ecohydraulic laboratory studies focusing on turbulence and biomechanisms which different species and sizes can use to exploit unsteady flow could provide valuable insights. Such insights and information relate to fish passage effectiveness and are important for the sustainability of fish populations.

\section{Acknowledgements}

We thank the staff of the National Laboratory for Civil Engineering (LNEC), Lisbon, for the valuable assistance during this study. Thanks are extended to Teresa Alvarez and Paulo Branco for their support in the experimental and fieldwork. Funding for the study was provided by the Technology and Science Foundation (FCT) in the form of a PhD scholarship undertaken by Ana T. Silva (BD/19859/2004).

\section{References}

Alvarez, T.P., 2009. Caracterização da turbulência em passagens para peixes po bacias sucessivas com escoamento através de orifícios de fundo. Tese de Mestrado em Engenharia Civil, Instituto Superior Técnico, Lisboa.

Arthington, A.H., Welcomme, R.L., 1995. The condition of large rivers systems of the world. In: Armantrout, N.B., Wolotira Jr., R.J. (Eds.), Condition of the World's Aquatic Habitats. World Fisheries Congress, Science Publishers, Lebanon, New Hampshire, pp. 44-75.

Baras, E., Lambert, H., Philippart, J.C., 1994. A comprehensive assessment of the failure of Barbus barbus spawing migrations through a fish pass in the canalized River Meuse (Belgium). Aquat. Living Resour. 7, 181-189.

Bell, M.C., 1986. Fisheries Handbook of Engineering Requirements and Biologica Criteria. Fish Eng. Res. Prog. U. S. Army Corps of Eng., North Pacific Div., Portland, OR, p. 290.

Bioly, P., Magnan, P., 2002. Relationship between individual variation in morphological characters and swimming costs in brook char (Salvelinus fontinalis) and yellow perch (Perca flavescens). J. Exp. Biol. 205, 1031-1036.

Cada, G.F., Carlson, T., Ferguson, J., Richmond, M., Sale, M., 1999. Exploring the role of shear stress and severe turbulence in downstream fish passage. In: Brookshier P.A. (Ed.), Proceedings of waterpower'99. Hydro's Future: Technology, Markets, and Policy. American Society of Civil Engineers, Reston, VA, 10 pp.

Clay, C.H., 1995. Design of Fishways and Other Fish Facilities, 2nd ed. Lewis Publishers, Boca Raton, LA, 248 pp.
Collares-Pereira, M.J., Magalhães, M.F., Geraldes, A.M., Coelho, M.M., 1995. Riparian ecotones and spatial variation of fish assemblages in Portuguese lowland streams. Hydrobiologia 303, 93-101.

Cotel, A.J., Webb, P.W., Tritico, H., 2006. Do brown trout choose locations with reduce turbulence? Trans. Am. Fish. Soc. 135, 610-619.

Cowx, I.G., Welcomme, R.L., 1998. Rehabilitation of rivers for fish. Fishing New Books, Oxford.

Doadrio, I., 2001. Atlas y libro rojo de los peces continentales de España. Museo Nacional de Ciencias Naturales, Madrid.

Durbin, J., Watson, G.S., 1951. Testing for serial correlation in least squares regression II. Biometrika 38, 159-178.

Ead, S.A., Katopodis, C., Sikora, G.J., Rajaratnam, N., 2004. Flow regimes and structure in pool and fishways. J. Environ. Eng. Sci. 3, 379-390.

Enders, E.C., Boisclair, D., Roy, A.G., 2003. The effect of turbulence on the cost of swimming for juvenile Atlantic salmon (Salmo salar). Can. J. Fish. Aquat. Sci. 60, 1149-1160.

Enders, E.C., Boisclair, D., Roy, A.G., 2005. A model of the total swimming costs in turbulent flow for Atlantic salmon (Salmo salar). Can. J. Fish. Aquat. Sci. 62, 1079-1089.

FAO/DVWK, 2002. Fish Passes-Design, Dimensions and Monitoring. FAO, Rome

Geraldes, A.M., Coelho, M.M., Collares-Pereira, A.M., 1993. Régime alimentaire et croissance du barbeau ibérique. Barbus bocagei (Steind 1865) dans la Rivère Sorraia (Portugal). Cahiers d'Ethologie 13 (2), 179-180.

Gowans, A.D., Armstrong, J.D., Priede, I.G., McKelvey, S., 2003. Movements of Atlantic salmon migrating upstream through a fish-pass complex in Scotland. Ecol. Freshw. Fish. 12, 177-189.

Hedenström, A., 1993. Migration by soaring or flapping flight in birds: the relative importance of energy cost and speed. Phil. Trans. R. Soc. Lond. B 342, 353-361.

Katopodis, C., 2002. Nature-mimicking fishways: concepts and practical applications. Keynote lecture. In: Proceedings of the 2nd Nordic International Symposium on Freshwater Fish Migration and Fish Passage, Evaluation and Development, 20-22 September 2001, Reykjavik, Iceland. Environmental Sciences and Technology, University of Oulu, Finland, pp. 87-93.

Katopodis, C., 2005. Developing a toolkit for fish passage, ecological flow management and fish habitat works. J. Hydraul. Res. 43, 451-467.

Kirkbride, A.D., 1993. Observations of the Influence of Bed Roughness on Turbulence Structure in Depth Limited Flows Over Gravel Beds. Turbulence: Perspectives on Flow and Sediment Transport. Wiley, Chichester, UK.

Knaepkens, G., Maerten, E., Eens, M., 2007. Performance of a pool-and-weir fish pass for small bottom-dwelling freshwater fish species in a regulated lowland river. Anim. Biol. 57 (4), 423-432.

Liao, J.C., Beal, D.N., Lauder, G.V., Triantafyllou, M.S., 2003. Fish exploiting vortices decrease muscle activity. Science 302, 1566-1569.

Liao, J.C., 2007. A review of fish swimming mechanics and behavior in altered flows. Phil. Trans. R. Soc. B 362, 1973-1993.

Lobón-Cerviá, J., 1982. Population analysis of the Iberian nose (Chondrostoma polylepis Stein, 1865) in the Jarama River. Vie Milieu 32, 139-148.

Lucas, M.C., Frear, P.A., 1997. Effects of a flow-gauging weir on the migratory behaviour of adult barbel, a riverine cyprinid. J. Fish Biol. 50, 382-396.

Lupandin, A.I., 2005. Effect of flow turbulence on swimming speed of fish. Biol. Bull. 32, 461-466.

Mallen-Cooper, M., 1994. Swimming ability of adult golden perch, Macquaria ambigua (Percichthyidae), and adult silver perch, Bidyanus bidyanus (Teraponidae), in an experimental vertical-slot fishway aust. J. Mar. Freshwater Res. 45, 191-198.

Martínez-Capel, F., García de Jalón, D., Werenitzkt, D., Baeza, D., Rodilla-alamá, M., 2009. Microhabitat use by three endemic Iberian cyprinids in Mediterranean rivers (Tagus River basin, Spain). Fish. Manag. Ecol. 16, 52-60.

Martínez-Capel, F., García de Jalón, D., 1999. Desarrollo de curvas de preferencia de microhabitat para Leuciscus pyrenaicus y Barbus bocagei por buceo en el rio jarama (Cuenca del Tajo). Limnetica 17, 71-83.

Mateus, C.S., Quintella, B.R., Almeida, P.R., 2008. The critical swimming speed of Iberian barbel Barbus bocagei in relation to size and sex. J. Fish. Biol. 73, 1783-1789.

Noonan, M.J., Grant, J.W.A., Jackson, C.D., 2011. A quantitative assessment of fish passage efficiency. Fish Fish., http://dx.doi.org/10.1111/j.1467-2979.2011.00445.x.

Odeh, M., Noreika, J.F., Haro, A., Maynard, A., Castro-Santos, T., 2002. Evaluation of the Effects of Turbulence on the Behavior of Migratory Fish. Bonneville Power Administration, Portland, OR, Final Report to the Bonneville Power Administration, Contract 00000022 , Project 200005700.

Pavlov, D.S., Lupandin, A.I., Skorobogatov, M.A., 2000. The effects of flow turbulence on the behavior and distribution of fish. J. Ichthyol. 40, S232-S261.

Pavlov, D.S., Skorobagatov, M.A., Shtaf, L.G., 1982. The critical current velocity of fish and the degree of flow turbulence. Rep. USSR Acad. Sci. 267, 1019-1021.

Pope, S.B., 2000. Turbulent Flows. Cambridge University Press.

Przybilla, A., Kunze, S., Rudert, A., Bleckmann, H., Brucker, C., 2010. Entraining in trout: a behavioural and hydrodynamic analysis. J. Exp. Biol. 213, 2976-2986.

Ristroph, L., Bergou, A.T., Guckenheimer, J., Wang, Z.J., Cohen, I., 2011. Paddling mode of forward flight in insects. Phys. Rev. Lett. 106, 178103.

Rodi, W., 1980. Turbulence Models and their Application in Hydraulics. IAHR, Delft, the Netherlands (IAHR Monograph).

Santos, J.M., Ferreira, M.T., Godinho, F.N., Bochechas, J., 2005. Efficacy of a naturelike bypass channel in a Portuguese lowland river. J. Appl. Ichthyol. 21, $381-388$ 
Sapir, N., Horvitz, N., Wilkelski, M., Avissar, R., Mahrer, Y., Nathan, R., 2011. Migration by soaring or flapping: numerical atmospheric simulations reveal that turbulence kinetic energy dictates bee-eater flight mode. Proc. Biol. Sci. 278, 3380-3386, http://dx.doi.org/10.1098/rspb.2011.0358.

Saunders, D.L., Meeuwig, J.J., Vicent, A.C.J., 2002. Freshwater protected areas: strategies for conservation. Conserv. Biol. 16, 30-41.

Shah, M.K., Tachie, M.F., 2009. Proper orthogonal decomposition of pressure gradient flows downstream of a transverse square rib. AIAA J. 47 (11), 2616-2631.

Shamloo, H., Rajaratnam, N., Katopodis, C., 2001. Hydraulics of simple habitat structures. IAHR J. Hydraul. Res. 39 (4), 351-366.

Silva, A.T., Santos, J.M., Ferreira, M.T., Pinheiro, A.N., Katopodis, C., 2010. Passage efficiency of offset and straight orifices for upstream movements of Iberian barbel in a pool-type fishway. River Res. Appl., http://dx.doi.org/10.1002/rra.1465.

Silva, A.T., Santos, J.M., Ferreira, M.T., Pinheiro, A.N., Katopodis, C., 2011. Effects of water velocity and turbulence on the behaviour of Iberian barbell (Luciobarbus bocagei, Steindachner 1864) in an experimental pool-type fishway. River Res. Appl. 27, 360-373.

Smith, R.J.F., 1991. Social behaviour, homing and migration. In: Winfields, I.J., Nelson, J.S. (Eds.), Cyprinid Fishes-Systematics, Biology and Exploitation. Chapman \& Hall, London, pp. 509-529.

Smith, D.L., Brannon, E.L., 2005. Response of juvenile rainbow trout to turbulence produced by prismatoidal shapes. Trans. Am. Fish. Soc. 134, 741-753.

Smith, D.L., Brannon, E.L., Shafii, B., Odeh, M., 2006. Use of the average and fluctuating velocity components for estimation of volitional rainbow trout density. Trans. Am. Fish. Soc. 135 (2), 431-441.
STATSOFT, INC, 2000. Statistica for Windows (Computer Program Manual). Statsoft, Inc, Tulsa.

Tennekes, H., Lumley, J.L., 1972. A First Course in Turbulence. The MIT Press.

Triantafyllou, G.S., Techet, A.H., Zhu, Q., Beal, D.N., Hover, F.S., Yue, D.K.P., 2002 Vorticity control in fish-like propulsion and maneuvering. Integr. Comp. Biol. 42, 1026-1031.

Tritico, H.M., Cotel, A.J., 2010. The effects of turbulent eddies on the stability and critical swimming speed of creek chub (Semotilus atromaculatus). J. Exp. Biol. 213, 2284-2293.

Webb, P.W., 1988. Simple physical principles and vertebrate aquatic locomotion Am. Zool. 28, 709-725.

Webb, P.W., 2002. Control of posture, depth, and swimming trajectories of fishes. Integr. Comp. Biol. 42, 94-110.

Webb, P.W., 2004. Response latencies to postural disturbances in three species of teleostean fishes. J. Exp. Biol. 207, 955-961.

Webb, P.W., 2006. Stability and maneuverability. In: Shadwick, R.E., Lauder, G.V. (Eds.), Fish Physiology. Elsevier Press, San Diego, pp. 281-332.

Webb, P.W., Cotel, A.J., 2010. Turbulence: does vorticity affect the structure and shape of body and fin propulsors? Integr. Comp. Biol. 50 (6), 11551166 .

Weihs, D., 2002. Stability versus maneuverability in aquatic locomotion. Integr. Comp. Biol. 42, 127-134.

Zar, J.H., 1996. Biostatistical Analysis. Prentice Hall International, Inc., New Jersey, USA. 